\title{
POTENTIAL HYDROLOGI FOR IRRIGATION LOCATION- CANDIDATE LOCATION OF PADDY FIELD IN EAST BARITO DISTRICT OF CENTRAL KALIMANTAN
}

\section{Potensi Pengairan Untuk Irigasi Calon Lokasi- Lahan Cetak Sawah Di Kabupaten Barito Timur Kalimantan Tengah}

\author{
Lola Cassiophea ${ }^{1)}$ \\ 1)Jurusan Teknologi dan Kejuruan Prodi Pendidikan Teknik Bangunan, FKIP, \\ Universitas Palangkaraya, Jl. H.Timang Tunjung Nyaho Palangkaraya Kode Pos 73112 \\ e-mail: Il_cassiophea@yahoo.com
}

\begin{abstract}
This district of Katigan is a small part of the entire area and land surveys for the purposes of paddy field printing of the Central Kalimantan Provincial Agriculture Office. This activity aims to find the feasibility of irrigation potential that will flow through the paddy fields that have been in clean and clear condition in terms of the area, included in the category of decent land for rice crops, and the existence of adequate water sources to flow the rice fields. The water requirement for plants is basically obtainable directly from the rain water, the rainfall each season will not be the same. Therefore, we need a way to manage water with a need to manage water optimally, one of them is the use of irrigation system. The planned irrigation system for the Katingan irrigation area and its surroundings is a gravity irrigation system. The irrigation network used is a technical irrigation network. The total irrigation area is $352,6 \mathrm{Ha}$. The planned plot is 3 plots with the area of each plot between 3,6 ha to $99,9 \mathrm{Ha}$. The water requirement per hectare before adjusting to the efficiency of each channel is planned to be $1.2 \mathrm{ltr} / \mathrm{s} / \mathrm{ha}$.
\end{abstract}

Key words: Potency of irrigation, irrigation, paddy field

\begin{abstract}
ABSTRAK
Kabupaten Pulang Pisau ini adalah bagian kecil dari survei kawasan dan lahan secara keseluruhan untuk keperluan cetak sawah Dinas Pertanian Provinsi Kalimantan Tengah. Kegiatan ini bertujuan untuk mencari kelayakan potensi pengairan yang nantinya akan mengaliri sawah-sawah yang sudah dalam kondisi clean and clear dari segi kawasan, masuk dalam kategori tanah yang layak untuk tanaman padi, dan adanya sumber air yang memadai untuk mengaliri sawah. Kebutuhan air untuk tanaman pada dasarnya dapat diperoleh secara langsung dari air hujan, curah hujan tiap musimnya tidak akan sama. Oleh karena itu, dibutuhkan suatu cara untuk mengelola air dengan dibutuhkan suatu cara untuk mengelola air dengan optimal, salah satunya ialah dengan penggunaan sistem irigasi. Sistem irigasi yang direncanakan untuk daerah irigasi Katingan dan sekitarnya adalah sistem irigasi gravitasi. Jaringan irigasi yang digunakan adalah jaringan irigasi teknis. Luas daerah irigasi yang dialiri adalah 352,6 Ha. Petak sawah yang direncanakan adalah sebanyak 10 petak dengan luas masing-masing petak antara 3,6 ha hingga 99,9 $\mathrm{Ha}$. Kebutuhan air setiap hektar sebelum disesuaikan dengan efisiensi tiap saluran direncanakan sebesar $1.2 \mathrm{l} / \mathrm{det} / \mathrm{ha}$.
\end{abstract}

Kata-kata kunci : potensi pengairan, irigasi, cetak sawah

\section{PENDAHULUAN}

Banyak tempat di dunia terjadi kekurangan persediaan air akibat dari pengelolaan sumber daya air yang kurang baik. Hal ini dapat menimbulkan konflik, mengingat bahwa kersediaan pangan di suatu daerah memiliki kaitan erat dengan ketersediaan air di daerah tersebut. Jumlah penduduk dunia yang semakin meningkat dari hari ke hari mengakibatkan kebutuhan akan bahan pangan juga terus menerus bertambah. Untuk itu diperlukan suatu usaha untuk meningkatkan hasil pertanian yang ada. Salah satu cara adalah dengan pemenuhan kebutuhan pengairan yang merupakan hal terpenting dalam pertanian sebab tidak semua daerah mendapatkan pengairan yang mencukupi.

Istilah irigasi menurut PP Nomor : 7 tahun 2001 adalah usaha manusia di dalam menyediakan dan pengaturan air untuk menunjang pertanian yang jenisnya meliputi irigasi permukaan, irigasi bawah tanah, irigasi pompa dan irigasi tambak. Irigasi di maksudkan sebagai 
usaha penyediaan dan pengaturan air untuk menunjang pertaniaan (PP Nomor 22 tahun 1982).

Kegiatan survei potensi pengairan cetak sawah di Kabupaten Katigan ini adalah bagian kecil dari survei kawasan dan lahan secara keseluruhan untuk keperluan cetak sawah Dinas Pertanian Provinsi Kalimantan Tengah. Kegiatan ini bertujuan untuk mencari kelayakan potensi pengairan yang nantinya akan mengaliri sawah-sawah yang sudah dalam kondisi clean and clear dari segi kawasan, masuk dalam kategori tanah yang layak untuk tanaman padi, dan adanya sumber air yang memadai untuk mengaliri sawah. Kebutuhan air untuk tanaman pada dasarnya dapat diperoleh secara langsung dari air hujan.

\section{METODE PENELITIAN}

Lahan yang akan diteliti adalah tiga lahan kelompok tani di Kecamatan Maliku di Kabupaten Pulang Pisau yaitu Desa Sidodadi. Pengamatan ini bertujuan untuk untuk mencari daerah tangkapan air (DTA) sumber air dan sebaran debit bulanan dalam siklus satu tahun, mencari informasi sumber air (lokasi, elevasi dan jarak sumber air), pengukuran debit pada mata air dan sungai (pasang surut dan non pasang surut), analisis kecukupan air untuk irigasi, peta situasi titik sumber pengambilan air, serta sarana dan prasarana yang dibutuhkan untuk pengairan. Dalam pengamatan di lapangan yaitu :

1. Pemantauan lokasi dan menetukan titik perhitngan,

2. Pengambilan data lapangan,

3. Dokumentasi lapangan,

4. Mencari sumber air (lokasi, elevasi dan jarak sumber air),

5. Menghitung debit sumber air

Metodologi berkaitan dengan tata cara perhitungan kebutuhan air untuk irigasi meliputi perhitungan curah hujan stasiun hujan terdekat, debit andalan, iklim (kecepatan angin, kelembaban udara,temperatur \& penyinaran matahari) dan evapotranspirasi, serta kebutuhan pengambilan air untuk tanaman.

\section{HASIL DAN PEMBAHASAN}

Berdasarkan kriteria kelayakan calon lokasi perluasan sawah yang tercantum pada Pedoman Teknis Survei dan Investigasi Calon Petani - Calon Lokasi Perluasan Sawah dari Dinas Tanaman Pangan, Holtikultura dan Peternakan 2017, disebutkan bahwa pelaksanaan perencanaan perluasan sawah berfokus pada pengembangan lahan sawah baru yang memiliki sumber air, baik sumber air permukaan maupun air tanah. Setelah dilakukan survei potensi pengairan di Kabupaten Barito Timur diketahui bahwa seluruh sumber air yang ada merupakan air permukaan.
Lebar sungai dan saluran buatan bervariasi. Aliran sungai dan saluran buatan pada saat pengukuran sebagian ada aliran (air mengalir) sebagian tidak ada aliran (air tidak mengalir/kondisi diam).

Adapun hasil survei potensi pengairan dapat dilihat selengkapnya pada Tabel

\section{Lokasi Daerah Aliran Sungai}

Daerah Aliran Sungai (DAS) dari penelitian ini adalah gabungan dari sungai-sungai termasuk sungai musiman, diantaranya:

- Sungai Kalu Lungai

- Sungai Guha

- $\quad$ Sungai Liang

- $\quad$ Sungai Siong

- Sungai Rangkai

- Sungai Telang

- Sungai Palepek

- Sungai Bambulung

- Sungai Tuyau

\section{Perhitungan Ketersediaan Air Daerah Irigasi Barito} Timur

Untuk menghitung ketersediaan air, digunakan curah hujan $80 \%$. Cara mencari $R_{80}$ adalah sebagai berikut.

1. Mengumpulkan data curah hujan bulanan selama kurun waktu $\mathrm{n}$ tahun dari beberapa stasiun curah hujan yang terdekat dengan daerah rencana pengembangan irigasi. Pada perhitungan ini, digunakan data curah hujan selama 10 tahun dan minimal diperlukan 3 stasiun curah hujan.

2. Merata-ratakan data curah hujan yang diperoleh dari stasiun-stasiun tersebut.

3. Mengurutkan (sorting) data curah hujan per bulan tersebut dari yang terbesar hingga terkecil, dimana data pertama berarti $\mathrm{m}=1$.

4. Mencari probabilitas dari data curah hujan yang telah diurutkan dengan cara

$P=\frac{m}{n+1} \times 100 \%$

5. Mencari $R_{80}$ dengan menggunakan regresi linier. Menghitung Re dimana $\operatorname{Re}=0.7 * R_{80}$.

Perhitungan Kebutuhan Air Daerah Irigasi Katingan Untuk menghitung kebutuhan air daerah irigasi Sungai Katingan dilakukan langkah-langkah sebagai berikut .

1. Mencari data iklim selama 10 tahun (2006-2016) untuk daerah irigasi yang ditinjau. Untuk daerah irigasi Sungai Katingan data iklim diambil dari. Adapun data-data yang diperlukan adalah sebagai berikut. 

a. Temperatur rata-rata ( $\mathrm{T}$ ) oC selama 10 tahun
b. Kelembaban rata-rata (Rh) \% selama 10 tahun
c. Kelembaban maksimum (Rhmaks) \% selama 10 tahun
d. Kecepatan angin rata-rata (U) $\mathrm{km} /$ hari selama 10 tahun
e. Penyinaran matahari rata-rata $(n / N) \%$

2. Dari data-data dicari nilai rata-rata setiap bulannya, maka dapat dilakukan perhitungan evatransporasi potensial setiap bulannya. Untuk menghitung nilai evapotranspirasi potensial (ETo) digunakan metode Penman Modifikasi.

Contoh perhitungan untuk awal Bulan Januari Perhitungan ETo dengan metode Penman adalah sebagai berikut.

Langkah 1 : Data iklim bulan Januari

Temperatur rata-rata $(\mathrm{T})$

$25.60^{\circ} \mathrm{C}$

Kelembaban rata-rata (Rh)

$85.50 \%$

Penyinaran matahari rata-rata $(\mathrm{n} / \mathrm{N})$

$44.00 \%$

Kecepatan angin rata-rata $(U)$

4 knot

Kecepatan angin rata-rata (U)

$182.73 \mathrm{~km} /$ hari

Langkah 2 : Mencari nilai tekanan uap jenuh (ea)

Temperatur rata-rata $(\mathrm{T})$

$25.60^{\circ} \mathrm{C}$

Tekanan uap jenuh (ea)

$32.84 \mathrm{mmHg}$

Dengan menginterpolasi dari data

yang sudah ada.

Langkah 3 : Mencari harga Rh/100

$\mathrm{Rh}=85.50$

$\mathrm{Rh} / 100=0.8550$

Langkah 4 : Mencari tekanan uap nyata (ed) ed $=$ ea $\times \mathrm{Rh} / 100=32.84 \times 0.8550=$ $28.08 \mathrm{mmHg}$

Langkah 5 : Mencari harga (ea - ed) perbedaan tekanan uap air $(\mathrm{mmHg})$ ea-ed $=32.84-28.08=4.76$

Langkah 6 : Mencari harga kecepatan angin ratarata

Dari data didapatkan harga kecepatan angin rata-rata adalah $182.73 \mathrm{~km} /$ hari.

Langkah 7 : Mencari harga fungsi kecepatan angin

$f(U)=0.27(1+U / 100)=0.27(1+$ $182.73 / 100)=0.76$

Langkah 8 : Mencari faktor harga berat (W) dan
(1-W)

Nilai tersebut didapatkan dari interpolasi data yang sudah ada. Dari perhitungan didapatkan: $\mathrm{W}=0.73$ dan $(1-\mathrm{W})=0,27$

Langkah 9 : Mencari harga $(1-W) \times f(U) \times($ ea-ed) $(1-W) \times f(U) \times($ ea-ed $)=0.27 \times 0.76 \times$ $4.76=0.98$

Langkah 10 : Mencari harga ( $\mathrm{Ra}$ ) penyinaran radiasi matahari teoritis ( $\mathrm{mm} /$ hari) $\mathrm{Hal}$ ini sama dengan kasus kasus sebelumnya yaitu dengan menggunakan interpolasi dari data yang sudah ada.

$\mathrm{Ra}=15.66 \mathrm{~mm} /$ hari

Langkah 11 : Mencari harga $\mathrm{n} / \mathrm{N}$

$\mathrm{n} / \mathrm{N}=44 / 100=0.44$

Langkah 12 : Mencari harga Rs $\mathrm{Rs}=(0.25+(0.5 \times \mathrm{n} / \mathrm{N})) \times \mathrm{Ra}=(0.25+$ $(0.5 \times 0.44)) \times 15.66=7.33 \mathrm{~mm} /$ hari

Langkah 13 : Mencari harga radiasi penyinaran matahari yang diserap bumi (Rns) Didapat dari tabel atau menggunakan rumus.

Rns $=(1-w) \times R s=0.27 \times 7.33=$ $5.50 \mathrm{~mm} /$ hari

Langkah 14 : Mencari harga koreksi akibat temperatur $f(T)$

Dengan interpolasi data.

$\mathrm{T}=25.60^{\circ} \mathrm{C}$, maka

$f(T)=15.80$

Langkah 15 : Mencari harga koreksi akibat tekanan air $f(e d)$

$f(e d)=(0.34-(0.044 \times$ ed $\times 0.5)=(0.34$

$-(0.044 \times 28.08 \times 0.5)=0.11$

Langkah 16 : Mencari harga $f(n / N)$

$f(n / N)=0.1+0.9(n / N)=0.1+0.9(0.44)=$ 0.49

Langkah 17 : Mencari harga radiasi matahari yang dipancarkan bumi $(\mathrm{Rnl})$

$\mathrm{Rnl}=\mathrm{f}(\mathrm{T}) \times \mathrm{f}(\mathrm{ed}) \times \mathrm{f}(\mathrm{n} / \mathrm{N})=15.80 \times 0.11 \times$ $0.49=0.83 \mathrm{~mm} / \mathrm{hari}$

Langkah 18: Mencari harga radiasi matahari yang dipancarkan bumi (Rn)

$\mathrm{Rn}=\mathrm{Rns}-\mathrm{Rnl}=5.50-0.83=4.67$ $\mathrm{mm} /$ hari

Langkah 19 : Mencari faktor pengali pengganti kondisi cuaca akibat siang dan malam (C) $\mathrm{C}=1.05$

Langkah 20 : Perhitungan ETo (mm/hari) ETo $=\mathrm{C} \times(\mathrm{W} \times \mathrm{Rn}+(1-\mathrm{W}) \times \mathrm{f}(\mathrm{U}) \times($ ea-ed $)$ ETo $=1.05 \times(0.73 \times 4.67 \times 0.27 \times 0.76 \times$ 
4.76)

$\mathrm{ETo}=4.59$

Maka ETo untuk bulan November adalah $4.59 \mathrm{~mm} /$ hari.

3. Menghitung curah hujan efektif

Untuk irigasi padi, curah hujan efektif bulanan diambil $70 \%$ dari curah hujan minimum tengah bulanan dengan periode ulang 5 tahun, dihitung dengan rumus :

$\mathrm{Re}=0.7 \mathrm{R} 80(\mathrm{~mm} / \mathrm{hari})$

Untuk bulan Januari:

$\mathrm{Re}=358.30 \mathrm{~mm} / \mathrm{hari}$

4. Menghitung kebutuhan air di sawah untuk petak tersier

Perhitungan kebutuhan air di sawah dapat dilihat pada tabel. Langkah-langkah perhitungannya adalah sebagai berikut:

Baris 1 : Periode tanaman, dimulai pada bulan November tengah bulan pertama

Baris 2

: Evapotranspirasi potensial (ETo) (mm/hari)

Untuk bulan November, ETo $=6.08$ $\mathrm{mm} /$ hari

Baris 3 : Nilai kehilangan air akibat perkolasi tanaman (P) (mm/hari)

Diambil nilai $P=2 \mathrm{~mm} /$ hari

Baris $4 \quad$ : Curah hujan efektif $(\mathrm{Re})(\mathrm{mm} /$ hari) Nilai Re diambil dari tabel, yaitu Re50 dan $\operatorname{Re} 80$

Untuk bulan November periode I, $\operatorname{Re} 50=5.62 \mathrm{~mm} /$ hari

Baris 5 : Penggantian lapisan air (WLR)

Untuk penyiapan lahan 1,5 bulan dilakukan pemasukan nilai 1,1 sampai dengan 2,2 yang dilakukan pada bulan Desember periode II untuk alternatif $A$, bulan Januari periode I untuk alternatif B, dan bulan Januari periode II untuk alternatif $\mathrm{C}$.

Baris $6 \quad$ : Koefisien tanaman (C1) didasarkan pada ketentuan yang ada pada KP penunjang

Baris $7 \quad$ : Koefisien tanaman (C2) didasarkan pada ketentuan yang ada pada KP penunjang

Baris 8 : Koefisien tanaman (C3) didasarkan pada ketentuan yang ada pada KP penunjang

Baris 9 : Koefisien rata-rata tanaman (C) $\mathrm{C}=(\mathrm{C} 1+\mathrm{C} 2+\mathrm{C} 3) / 3$

Baris 10 : Penggunaan air untuk masa penyiapan lahan ( $\mathrm{mm} / \mathrm{hari})$, menggunakan rumus, LP = M.ek /

(ek - 1)

dimana :
M : Kebutuhan air untuk mengganti/mengkompensasi kehilangan air akibat evaporasi dan perkolasi di sawah yang sudah dijenuhkan

$\mathrm{M}=\mathrm{Eo}+\mathrm{P}$

$E \mathrm{E}=1,1 \times$ Eto

$\mathrm{P}=$ perkolasi

$\mathrm{k}=\mathrm{M} \times \mathrm{T} / \mathrm{S}$

$\mathrm{T}=$ Jangka waktu penyiapan lahan, hari

$S=$ Kebutuhan air untuk penjenuhan

ditambah dengan lapisan air $50 \mathrm{~mm}$

yakni $200+50=250 \mathrm{~mm}$ seperti yang

sudah diterangkan diatas

Untuk bulan November periode I, LP = $11.93 \mathrm{~mm} /$ hari

Baris 11 : Penggunaan air konsumtif untuk tanaman (Etc)

$\mathrm{ETC}=\mathrm{C} \times$ Eto

Untuk November Periode I (masa

penyiapan lahan)

Etc $=\mathrm{LP}=11.93 \mathrm{~mm} /$ hari

Baris 12

: Kebutuhan air bersih di sawah untuk padi, NFR (Netto Field Requirement)

Untuk masa penyiapan lahan,

$\mathrm{NFR}=\mathrm{LP}-\mathrm{Re}$

Untuk tanaman padi,

$\mathrm{NFR}=\mathrm{ETC}+\mathrm{WLR}+\mathrm{P}-\mathrm{Re}$

Untuk tanaman palawija,

$\mathrm{NFR}=\mathrm{Etc}+\mathrm{P}-\mathrm{Re}$

Karena pada bulan November periode I, lahan sedang dalam masa persiapan maka,

$\mathrm{NFR}=11.93+2-4.55=9.38$

$\mathrm{mm} /$ hari

Baris 13 : Kebutuhan air netto sebelum dibagi dengan efisiensi (DR $x$ eff) (l/det/ha)

$\mathrm{DR}=\mathrm{NFR} / 8.64$

November Periode I,

$\mathrm{DR}=9.38 / 8.64=1.67 \mathrm{I} / \mathrm{det} / \mathrm{ha}$

5. Menghitung kebutuhan air masing-masing golongan Perhitungan ini ditujukan untuk mengetahui perubahan kebutuhan air akibat rotasi teknis. Dalam perencanaan irigasi untuk daerah irigasi Sungai Katingan digunakan rotasi teknis. Adapun alternatifalternatif tersebut adalah sebagai berikut.

Golongan I : Alternatif A, mulai tanggal 1 November

Golongan II : Alternatif B, mulai tanggal 15 November

Golongan III : Alternatif C, mulai tanggal 1 Desember 
Golongan IV : Alternatif $(A+B) / 2$

Golongan $V$ : Alternatif $(B+C) / 2$

Golongan $\mathrm{VI} \quad$ : Alternatif $(\mathrm{A}+\mathrm{B}+\mathrm{C}) / 3$

Pada tabel dapat dilihat kebutuhan air untuk masingmasing golongan. Golongan yang dipilih adalah golongan I (alternatif A), yang memiliki DRmaks terbesar, DRmaks $=1.2$.

\section{Evaluasi Keseimbangan Air Daerah Irigasi Barito Timur}

Setelah mengetahui besarnya kebutuhan air di sawah (q), debit andalan $80 \%\left(\mathrm{Q}_{80}\right)$ tiap periode $1 / 2$ bulanan, maka dapat dihitung besarnya total daerah yang dapat dialiri tiap periode. Dari hasil perhitungan yang penulis lakukan, diketahui besarnya total daerah yang dapat dialiri oleh Sungai Barito adalah sebesar 352,6 Ha. Dengan demikian maka dapat dikatakan daerah sawah yang penulis rencanakan dapat terairi dengan baik.

Tabel 4.1 Hasil Perhitungan Evapotranspirasi Janggi

\begin{tabular}{|c|c|c|c|c|c|c|c|c|c|c|c|c|c|c|}
\hline \begin{tabular}{l|l|} 
No & Parameter \\
\end{tabular} & Satuan & Perolehan Nilai & Januari & Februari & Maret & April & Mei & Juni & Juli & Agustus & September & Oktober & November & \begin{tabular}{|l|} 
Desember \\
\end{tabular} \\
\hline$\left.1\right|_{T} ^{T}$ & c & data & 21,60 & 21,74 & 21,77 & 22,05 & 22,39 & 22,07 & 21,54 & 21,88 & 22,11 & 22,30 & 22,02 & 21,69 \\
\hline 2 ea & mbar & tabel + interpolasi & 25,97 & 26,21 & 26,26 & 26,75 & 27,35 & 26,78 & 25,87 & 26,45 & 26,85 & 27,19 & 26,69 & 26,12 \\
\hline 3 Rh & $\%$ & data & $85 \%$ & $87 \%$ & $84 \%$ & $84 \%$ & $84 \%$ & $84 \%$ & $80 \%$ & $75 \%$ & $77 \%$ & $79 \%$ & $82 \%$ & $84 \%$ \\
\hline 4ed & mbar & $(2) *(3)$ & 22,07 & 22,80 & 22,06 & 22,47 & 22,97 & 22,50 & 20,69 & 19,84 & 20,68 & 21,48 & 21,89 & 21,94 \\
\hline 5 ea-ed & mbar & (2)- (4) & 3,90 & 3,41 & 4,20 & 4,28 & 4,38 & 4,29 & 5,17 & 6,61 & 6,18 & 5,71 & 4,81 & 4,18 \\
\hline 60 & $\mathrm{~km} / \mathrm{hr}$ & data & 294,61 & 294,61 & 260,47 & 250,14 & 266,82 & 247,06 & 252,00 & 300,17 & 266,82 & 266,82 & 256,94 & 304,94 \\
\hline $7 \mid f(U)$ & & $0,27^{*}(1+(6) / 100)$ & 0,80 & 0,80 & 0,71 & 0,68 & 0,72 & 0,67 & 0,68 & 0,81 & 0,72 & 0,72 & 0,70 & 0,83 \\
\hline \begin{tabular}{l|l|l|}
$8 \mid w$ \\
\end{tabular} & & tabel + interpolasi & 0,74 & 0,74 & 0,74 & 0,74 & 0,74 & 0,74 & 0,73 & 0,74 & 0,74 & 0,74 & 0,74 & 0,73 \\
\hline $9(1-w)$ & & $1-(8)$ & 0,26 & 0,26 & 0,26 & 0,26 & 0,26 & 0,26 & 0,27 & 0,26 & 0,26 & 0,26 & 0,26 & 0,27 \\
\hline $10\left[\left(1-w w^{*} f(U)^{*}(e-e d)\right.\right.$ & $\mathrm{mm} / \mathrm{hr}$ & $\mid(9)^{*}(7)^{*}(5)$ & 0,82 & 0,72 & 0,77 & 0,74 & 0,83 & 0,75 & 0,94 & 1,41 & 1,16 & 1,05 & 0,86 & 0,92 \\
\hline 11 Ra & $\mathrm{mm} / \mathrm{hr}$ & tabel + interpolasi & 16,02 & 16,07 & 15,53 & 14,48 & 13,18 & 12,51 & 12,81 & 13,78 & 14,93 & 15,77 & 15,95 & 15,92 \\
\hline \begin{tabular}{l|l}
$12 \mathrm{n} / \mathrm{N}$ \\
\end{tabular} & $\%$ & data & $46,33 \%$ & $50,00 \%$ & $43,50 \%$ & $43,00 \%$ & $60,00 \%$ & $62,67 \%$ & $62,00 \%$ & $54,00 \%$ & $64,33 \%$ & $47,75 \%$ & $49,50 \%$ & $49,67 \%$ \\
\hline $13(0,25+0,5 n / N)$ & & $0,25+0,5^{*}(12)$ & 0,48 & 0,50 & 0,47 & 0,47 & 0,55 & 0,56 & 0,56 & 0,52 & 0,57 & 0,49 & 0,50 & 0,50 \\
\hline 14 Rs & $\mathrm{mm} / \mathrm{hr}$ & $(11)^{*}(13)$ & 7,72 & 8,04 & 7,26 & 6,73 & 7,25 & 7,05 & 7,17 & 7,17 & 8,53 & 7,71 & 7,93 & 7,93 \\
\hline 15 & & konstanta & 0,25 & 0,25 & 0,25 & 0,25 & 0,25 & 0,25 & 0,25 & 0,25 & 0,25 & 0,25 & 0,25 & 0,25 \\
\hline 16 Rns & $\mathrm{mm} / \mathrm{hr}$ & $(1-(15))^{*}(14)$ & 5,79 & 6,03 & 5,44 & 5,05 & 5,44 & 5,28 & 5,38 & 5,37 & 6,40 & 5,78 & 5,95 & 5,95 \\
\hline $17 f(T)$ & & tabel + interpolasi & 15,17 & 15,17 & 15,29 & 15,39 & 15,48 & 15,20 & 15,13 & 15,22 & 15,28 & 15,37 & 15,32 & 15,16 \\
\hline $18 / f($ led $)$ & mbar & $0,34-\left(0,044^{*}\right.$ akar $\left.(4)\right)$ & 0,13 & 0,13 & 0,13 & 0,13 & 0,13 & 0,13 & 0,14 & 0,14 & 0,14 & 0,14 & 0,13 & 0,13 \\
\hline $19 \mathrm{f}(\mathrm{n} / \mathrm{N})$ & & $0,1+0,,^{*}(12)$ & 0,52 & 0,55 & 0,49 & 0,49 & 0,64 & 0,66 & 0,66 & 0,59 & 0,68 & 0,53 & 0,55 & 0,55 \\
\hline $20 \mid \operatorname{Rn} 1$ & $\mathrm{~mm} / \mathrm{hr}$ & $\mid(17)^{*}(18)^{*}(19)$ & 1,05 & 1,08 & 1,00 & 0,98 & 1,28 & 1,33 & 1,39 & 1,28 & 1,45 & 1,11 & 1,12 & 1,11 \\
\hline $21 \mathrm{Rn}$ & $\mathrm{mm} / \mathrm{hr}$ & $(16)-(20)$ & 4,74 & 4,94 & 4,44 & 4,07 & 4,16 & 3,96 & 3,99 & 4,09 & 4,95 & 4,67 & 4,83 & 4,84 \\
\hline \begin{tabular}{l|l}
22 & $w * R n$ \\
\end{tabular} & $\mathrm{~mm} / \mathrm{hr}$ & $(8)^{*}(21)$ & 3,49 & 3,64 & 3,29 & 3,02 & 3,07 & 2,92 & 2,92 & 3,02 & 3,67 & 3,48 & 3,59 & 3,56 \\
\hline \begin{tabular}{|l|l}
23 & Rhmax \\
\end{tabular} & $\%$ & data & $85,00 \%$ & $86,00 \%$ & $86,00 \%$ & $87,00 \%$ & $86,00 \%$ & $86,00 \%$ & $86,00 \%$ & $78,00 \%$ & $82,00 \%$ & $81,00 \%$ & $84,00 \%$ & $87,00 \%$ \\
\hline $24 c$ & & tabel + interpolasi(asumsu Uday/night = 1) & 1,10 & 1,10 & 1,10 & 0,95 & 0,95 & 1,00 & 1,00 & 1,00 & 1,10 & 1,10 & 1,15 & 1,15 \\
\hline 25 Eto & $\mathrm{mm} / \mathrm{hr}$ & $((10)+(22))^{*}(24)$ & 4,74 & 4,79 & 4,47 & 3,58 & 3,70 & 3,67 & 3,87 & 4,43 & 5,31 & 4,99 & 5,11 & 5,14 \\
\hline
\end{tabular}

Sumber : Hasil Perhitungan 2017

Tabel 4.2 Hasil Perhitungan Evapotranspirasi Sei Guha

\begin{tabular}{|c|c|c|c|c|c|c|c|c|c|c|c|c|c|c|}
\hline Parameter & Satuan & Perolehan Nilai & Januari & \begin{tabular}{|l|} 
Februari \\
\end{tabular} & Maret & April & Mei & Juni & Juli & \begin{tabular}{|l|} 
Agustus \\
\end{tabular} & September & \begin{tabular}{|l|} 
Oktober \\
\end{tabular} & \begin{tabular}{|l|} 
November \\
\end{tabular} & \begin{tabular}{|l|} 
Desember \\
\end{tabular} \\
\hline $1 \mathrm{~T}$ & c & data & 21,60 & 21,74 & 21,77 & 22,05 & 22,39 & 22,07 & 21,54 & 21,88 & 22,11 & 22,30 & 22,02 & 21,69 \\
\hline 2 ea & mbar & tabel + interpolasi & 25,97 & 26,21 & 26,26 & 26,75 & 27,35 & 26,78 & 25,87 & 26,45 & 26,85 & 27,19 & 26,69 & 26,12 \\
\hline 3 Rh & $\%$ & data & $85 \%$ & $87 \%$ & $84 \%$ & $84 \%$ & $84 \%$ & $84 \%$ & $80 \%$ & $75 \%$ & $77 \%$ & $79 \%$ & $82 \%$ & $84 \%$ \\
\hline 4 ed & mbar & $(2)^{*}(3)$ & 22,07 & 22,80 & 22,06 & 22,47 & 22,97 & 22,50 & 20,69 & 19,84 & 20,68 & 21,48 & 21,89 & 21,94 \\
\hline 5 ea-ed & mbar & $(2)-(4)$ & 3,90 & 3,41 & 4,20 & 4,28 & 4,38 & 4,29 & 5,17 & 6,61 & 6,18 & 5,71 & 4,81 & 4,18 \\
\hline $6 \|$ & $\mathrm{km} / \mathrm{hr}$ & data & 294,61 & 294,61 & 260,47 & 250,14 & 266,82 & 247,06 & 252,00 & \begin{tabular}{|l|l|}
300,17 \\
\end{tabular} & 266,82 & 266,82 & 256,94 & 304,94 \\
\hline \begin{tabular}{|l|l|l|}
$7(U)$ \\
\end{tabular} & & $0,27^{*}(1+(6) / 100)$ & 0,80 & 0,80 & 0,71 & 0,68 & 0,72 & 0,67 & 0,68 & 0,81 & 0,72 & 0,72 & 0,70 & 0,83 \\
\hline $8 \mid W$ & & tabel + interpolasi & 0,74 & 0,74 & 0,74 & 0,74 & 0,74 & 0,74 & 0,73 & 0,74 & 0,74 & 0,74 & 0,74 & 0,73 \\
\hline 9 (1-w) & & $1-(8)$ & 0,26 & 0,26 & 0,26 & 0,26 & 0,26 & 0,26 & 0,27 & 0,26 & 0,26 & 0,26 & 0,26 & 0,27 \\
\hline $10\left|(1-w)^{*} f(U)^{*}\right|(e a-e d)$ & $\mathrm{mm} / \mathrm{hr}$ & $(9)^{*}(7)^{*}(5)$ & 0,82 & 0,72 & 0,77 & 0,74 & 0,83 & 0,75 & 0,94 & 1,41 & 1,16 & 1,05 & 0,86 & 0,92 \\
\hline 11 Ra & $\mathrm{mm} / \mathrm{hr}$ & tabel + interpolasi & 16,02 & 16,07 & 15,53 & 14,48 & 13,18 & 12,51 & 12,81 & 13,78 & 14,93 & 15,77 & 15,95 & 15,92 \\
\hline $12 \mathrm{n} / \mathrm{N}$ & $\%$ & data & $46,33 \%$ & $50,00 \%$ & $43,50 \%$ & $43,00 \%$ & $60,00 \%$ & $62,67 \%$ & $62,00 \%$ & $54,00 \%$ & $64,33 \%$ & $47,75 \%$ & $49,50 \%$ & $49,67 \%$ \\
\hline $13(0,25+0,5 \mathrm{n} / \mathrm{N})$ & & $0,25+0,5^{*}(12)$ & 0,48 & 0,50 & 0,47 & 0,47 & 0,55 & 0,56 & 0,56 & 0,52 & 0,57 & 0,49 & 0,50 & 0,50 \\
\hline 14 Rs & $\mathrm{mm} / \mathrm{hr}$ & $\mid(11)^{*}(13)$ & 7,72 & 8,04 & 7,26 & 6,73 & 7,25 & 7,05 & 7,17 & 7,17 & 8,53 & 7,71 & 7,93 & 7,93 \\
\hline $15 \mid$ & & konstanta & 0,25 & 0,25 & 0,25 & 0,25 & 0,25 & 0,25 & 0,25 & 0,25 & 0,25 & 0,25 & 0,25 & 0,25 \\
\hline \begin{tabular}{|l|l|l|l}
16 Rns \\
\end{tabular} & $\mathrm{mm} / \mathrm{hr}$ & $(1-(15))^{*}(14)$ & 5,79 & 6,03 & 5,44 & 5,05 & 5,44 & 5,28 & 5,38 & 5,37 & 6,40 & 5,78 & 5,95 & 5,95 \\
\hline $177 f(T)$ & & tabel + interpolasi & 15,17 & 15,17 & 15,29 & 15,39 & 15,48 & 15,20 & 15,13 & 15,22 & 15,28 & 15,37 & 15,32 & 15,16 \\
\hline \begin{tabular}{|l|l|l|l|l|l}
18 fed \\
\end{tabular} & mbar & $0,34-(0,044 *$ akar $(4))$ & 0,13 & 0,13 & 0,13 & 0,13 & 0,13 & 0,13 & 0,14 & 0,14 & 0,14 & 0,14 & 0,13 & 0,13 \\
\hline $19 f(\ln / \mathrm{N})$ & & $0,1+0, * *(12)$ & 0,52 & 0,55 & 0,49 & 0,49 & 0,64 & 0,66 & 0,66 & 0,59 & 0,68 & 0,53 & 0,55 & 0,55 \\
\hline $20 \mathrm{Rn} 1$ & $\mathrm{~mm} / \mathrm{hr}$ & $(17)^{*}(18)^{*}(19)$ & 1,05 & 1,08 & 1,00 & 0,98 & 1,28 & 1,33 & 1,39 & 1,28 & 1,45 & 1,11 & 1,12 & 1,11 \\
\hline $21 \mathrm{Rn}$ & $\mathrm{mm} / \mathrm{hr}$ & $(16)-(20)$ & 4,74 & 4,94 & 4,44 & 4,07 & 4,16 & 3,96 & 3,99 & 4,09 & 4,95 & 4,67 & 4,83 & 4,84 \\
\hline \begin{tabular}{|l|l|l}
22 & W Rn \\
\end{tabular} & $\mathrm{mm} / \mathrm{hr}$ & $(8)^{*}(21)$ & 3,49 & 3,64 & 3,29 & 3,02 & 3,07 & 2,92 & 2,92 & 3,02 & 3,67 & 3,48 & 3,59 & 3,56 \\
\hline \begin{tabular}{|l|l|l|} 
Rhmax \\
\end{tabular} & $\%$ & data & $85,00 \%$ & $86,00 \%$ & $86,00 \%$ & $87,00 \%$ & $86,00 \%$ & $86,00 \%$ & $86,00 \%$ & $78,00 \%$ & $82,00 \%$ & $81,00 \%$ & $84,00 \%$ & $87,00 \%$ \\
\hline $24 \mathrm{C}$ & & tabel + interpolasi(asumsu Uday/night = 1) & 1,10 & 1,10 & 1,10 & 0,95 & 0,95 & 1,00 & 1,00 & 1,00 & 1,10 & 1,10 & 1,15 & 1,15 \\
\hline 25 Eto & $\mathrm{mm} / \mathrm{hr}$ & $((10)++(22) * *(24)$ & 4,74 & 4,79 & 4,47 & 3,58 & 3,70 & 3,67 & 3,87 & 4,43 & 5,31 & 4,99 & 5,11 & 5,14 \\
\hline
\end{tabular}

Sumber : Hasil Perhitungan 2017 
Tabel 4.3 Hasil Perhitungan Kebutuhan Air untuk Pengolahan dan Penyiapan Lahan `Janggi IR (Irrigation Requirement)

\begin{tabular}{|c|c|c|c|c|c|c|c|}
\hline Bulan & Eto (mm/hari) & Eo (mm/hari) & $\mathrm{P}$ (mm/hari) & $\mathrm{M}$ (mm/hari) & $\mathrm{T}$ (mm/hari) & $\mathrm{S}(\mathrm{mm})$ & $\mathrm{k}$ \\
\hline Jan-01 & 4,74 & 5,21 & 2,00 & 7,21 & 45,00 & 300,00 & 1,08 \\
\hline Jan-02 & 4,74 & 5,21 & 2,00 & 7,21 & 45,00 & 300,00 & 1,08 \\
\hline Feb-01 & 4,79 & 5,27 & 2,00 & 7,27 & 45,00 & 300,00 & 1,09 \\
\hline Feb-02 & 4,79 & 5,27 & 2,00 & 7,27 & 45,00 & 300,00 & 1,09 \\
\hline Mar-01 & 4,47 & 4,91 & 2,00 & 6,91 & 45,00 & 300,00 & 1,04 \\
\hline Mar-02 & 4,47 & 4,91 & 2,00 & 6,91 & 45,00 & 300,00 & 1,04 \\
\hline Apr-01 & 3,58 & 3,94 & 2,00 & 5,94 & 45,00 & 300,00 & 0,89 \\
\hline Apr-02 & 3,58 & 3,94 & 2,00 & 5,94 & 45,00 & 300,00 & 0,89 \\
\hline Mei-01 & 3,70 & 4,07 & 2,00 & 6,07 & 45,00 & 300,00 & 0,91 \\
\hline Mei-02 & 3,70 & 4,07 & 2,00 & 6,07 & 45,00 & 300,00 & 0,91 \\
\hline Jun-01 & 3,67 & 4,04 & 2,00 & 6,04 & 45,00 & 300,00 & 0,91 \\
\hline Jun-02 & 3,67 & 4,04 & 2,00 & 6,04 & 45,00 & 300,00 & 0,91 \\
\hline Jul-01 & 3,87 & 4,25 & 2,00 & 6,25 & 45,00 & 300,00 & 0,94 \\
\hline Jul-02 & 3,87 & 4,25 & 2,00 & 6,25 & 45,00 & 300,00 & 0,94 \\
\hline Agust-01 & 4,43 & 4,87 & 2,00 & 6,87 & 45,00 & 300,00 & 1,03 \\
\hline Agust-02 & 4,43 & 4,87 & 2,00 & 6,87 & 45,00 & 300,00 & 1,03 \\
\hline Sep-01 & 5,31 & 5,84 & 2,00 & 7,84 & 45,00 & 300,00 & 1,18 \\
\hline Sep-02 & 5,31 & 5,84 & 2,00 & 7,84 & 45,00 & 300,00 & 1,18 \\
\hline Okt-01 & 4,99 & 5,49 & 2,00 & 7,49 & 45,00 & 300,00 & 1,12 \\
\hline Okt-02 & 4,99 & 5,49 & 2,00 & 7,49 & 45,00 & 300,00 & 1,12 \\
\hline Nop-01 & 5,11 & 5,63 & 2,00 & 7,63 & 45,00 & 300,00 & 1,14 \\
\hline Nop-02 & 5,11 & 5,63 & 2,00 & 7,63 & 45,00 & 300,00 & 1,14 \\
\hline Des-01 & 5,14 & 5,66 & 2,00 & 7,66 & 45,00 & 300,00 & 1,15 \\
\hline Des-02 & 5,14 & 5,66 & 2,00 & 7,66 & 45,00 & 300,00 & 1,15 \\
\hline
\end{tabular}

Sumber : Hasil Perhitungan 2017

Tabel 4.4 Hasil Perhitungan Kebutuhan Air untuk Pengolahan dan Penyiapan Lahan Sei Guha IR (Irrigation Requirement)

\begin{tabular}{|c|c|c|c|c|c|c|c|c|}
\hline Bulan & Eto (mm/hari) & Eo (mm/hari) & $\mathrm{P}$ (mm/hari) & $\mathrm{M}$ (mm/hari) & $\mathrm{T}$ (mm/hari) & $\mathrm{S}$ (mm) & $\mathrm{k}$ & IR saat LP (mm/hari) \\
\hline Jan-01 & 4,74 & 5,21 & 2,00 & 7,21 & 45,00 & 300,00 & 1,08 & 10,91 \\
\hline Jan-02 & 4,74 & 5,21 & 2,00 & 7,21 & 45,00 & 300,00 & 1,08 & 10,91 \\
\hline Feb-01 & 4,79 & 5,27 & 2,00 & 7,27 & 45,00 & 300,00 & 1,09 & 10,95 \\
\hline Feb-02 & 4,79 & 5,27 & 2,00 & 7,27 & 45,00 & 300,00 & 1,09 & 10,95 \\
\hline Mar-01 & 4,47 & 4,91 & 2,00 & 6,91 & 45,00 & 300,00 & 1,04 & 10,71 \\
\hline Mar-02 & 4,47 & 4,91 & 2,00 & 6,91 & 45,00 & 300,00 & 1,04 & 10,71 \\
\hline Apr-01 & 3,58 & 3,94 & 2,00 & 5,94 & 45,00 & 300,00 & 0,89 & 10,07 \\
\hline Apr-02 & 3,58 & 3,94 & 2,00 & 5,94 & 45,00 & 300,00 & 0,89 & 10,07 \\
\hline Mei-01 & 3,70 & 4,07 & 2,00 & 6,07 & 45,00 & 300,00 & 0,91 & 10,16 \\
\hline Mei-02 & 3,70 & 4,07 & 2,00 & 6,07 & 45,00 & 300,00 & 0,91 & 10,16 \\
\hline Jun-01 & 3,67 & 4,04 & 2,00 & 6,04 & 45,00 & 300,00 & 0,91 & 10,14 \\
\hline Jun-02 & 3,67 & 4,04 & 2,00 & 6,04 & 45,00 & 300,00 & 0,91 & 10,14 \\
\hline Jul-01 & 3,87 & 4,25 & 2,00 & 6,25 & 45,00 & 300,00 & 0,94 & 10,27 \\
\hline Jul-02 & 3,87 & 4,25 & 2,00 & 6,25 & 45,00 & 300,00 & 0,94 & 10,27 \\
\hline Agust-01 & 4,43 & 4,87 & 2,00 & 6,87 & 45,00 & 300,00 & 1,03 & 10,68 \\
\hline Agust-02 & 4,43 & 4,87 & 2,00 & 6,87 & 45,00 & 300,00 & 1,03 & 10,68 \\
\hline Sep-01 & 5,31 & 5,84 & 2,00 & 7,84 & 45,00 & 300,00 & 1,18 & 11,34 \\
\hline Sep-02 & 5,31 & 5,84 & 2,00 & 7,84 & 45,00 & 300,00 & 1,18 & 11,34 \\
\hline Okt-01 & 4,99 & 5,49 & 2,00 & 7,49 & 45,00 & 300,00 & 1,12 & 11,10 \\
\hline Okt-02 & 4,99 & 5,49 & 2,00 & 7,49 & 45,00 & 300,00 & 1,12 & 11,10 \\
\hline Nop-01 & 5,11 & 5,63 & 2,00 & 7,63 & 45,00 & 300,00 & 1,14 & 11,19 \\
\hline Nop-02 & 5,11 & 5,63 & 2,00 & 7,63 & 45,00 & 300,00 & 1,14 & 11,19 \\
\hline Des-01 & 5,14 & 5,66 & 2,00 & 7,66 & 45,00 & 300,00 & 1,15 & 11,21 \\
\hline Des-02 & 5,14 & 5,66 & 2,00 & 7,66 & 45,00 & 300,00 & 1,15 & 11,21 \\
\hline
\end{tabular}


Tabel 4.5 Hasil Pemilihan Curah Hujan Efektif Janggi

\begin{tabular}{|c|c|c|c|c|c|c|c|c|c|c|c|c|}
\hline tahun/bulan & Januari & Februari & Maret & April & Mei & Juni & Juli & Agustus & September & Oktober & November & Desember \\
\hline 2007 & 0 & 0 & 0 & 0 & 0 & 0 & 0 & 0 & 0 & 0 & 0 & 0 \\
\hline 2008 & 0 & 0 & 0 & 0 & 27 & 24 & 30 & 19 & 12 & 27 & 31 & 127 \\
\hline 2009 & 130 & 117 & 93 & 156 & 58 & 42 & 36 & 15 & 17 & 60 & 121 & 178 \\
\hline 2010 & 194 & 77 & 55 & 144 & 75 & 106 & 102 & 126 & 83 & 163 & 110 & 156 \\
\hline 2011 & 149 & 93 & 127 & 140 & 78 & 42 & 20 & 24 & 49 & 50 & 64 & 137 \\
\hline 2012 & 128 & 138 & 113 & 40 & 106 & 39 & 16 & 74 & 10 & 25 & 64 & 92 \\
\hline 2013 & 68 & 80 & 27 & 13 & 29 & 10 & 30 & 21 & 40 & 17 & 41 & 34 \\
\hline 2014 & 32 & 11 & 14 & 0 & 0 & 0 & 39 & 57 & 10 & 12 & 64 & 93 \\
\hline 2015 & 104 & 67 & 0 & 0 & 0 & 0 & 0 & 0 & 0 & 0 & 0 & 0 \\
\hline 2016 & 0 & 0 & 0 & 0 & 0 & 0 & 0 & 0 & 0 & 0 & 0 & 0 \\
\hline
\end{tabular}

Tabel 4.6 Hasil Pemilihan Curah Hujan Efektif Janggi (setelah diurutkan)

\begin{tabular}{|r|c|c|c|c|c|c|c|c|c|c|c|c|c|r|}
\hline No & Tahun & Januari & Februari & Maret & April & Mei & Juni & Juli & Agustus & September & Oktober & November & Desember & Probabilitas \\
\hline 1 & 2007 & 194 & 138 & 127 & 156 & 106 & 106 & 102 & 126 & 83 & 163 & 121 & 178 & $9,09 \%$ \\
\hline 2 & 2008 & 149 & 117 & 113 & 144 & 78 & 42 & 39 & 74 & 49 & 60 & 110 & 156 & $18,18 \%$ \\
\hline 3 & 2009 & 130 & 93 & 93 & 140 & 75 & 42 & 36 & 57 & 40 & 50 & 64 & 137 & $27,27 \%$ \\
\hline 4 & 2010 & 128 & 80 & 55 & 40 & 58 & 39 & 30 & 24 & 17 & 27 & 64 & 127 & $36,36 \%$ \\
\hline 5 & 2011 & 104 & 77 & 27 & 13 & 29 & 24 & 30 & 21 & 12 & 25 & 64 & 93 & $45,45 \%$ \\
\hline 6 & 2012 & 68 & 67 & 14 & 0 & 27 & 10 & 20 & 19 & 10 & 17 & 41 & 92 & $54,55 \%$ \\
\hline 7 & 2013 & 32 & 11 & 0 & 0 & 0 & 0 & 16 & 15 & 10 & 12 & 31 & 34 & $63,64 \%$ \\
\hline 8 & 2014 & 0 & 0 & 0 & 0 & 0 & 0 & 0 & 0 & 0 & 0 & 0 & 0 & $72,73 \%$ \\
\hline 9 & 2015 & 0 & 0 & 0 & 0 & 0 & 0 & 0 & 0 & 0 & 0 & 0 & 0 & $81,82 \%$ \\
\hline 10 & 2016 & 0 & 0 & 0 & 0 & 0 & 0 & 0 & 0 & 0 & 0 & 0 & 0 & $90,91 \%$ \\
\hline
\end{tabular}

Sumber : Hasil Olah Data 2017

Tabel 4.7 Pemilihan Curah Hujan Efektif (Re) Untuk Tanaman Padi

\begin{tabular}{|r|c|c|c|c|c|}
\hline No & Bulan & $\mathrm{R} 80(\mathrm{~mm} / \mathrm{b} / \mathrm{n})$ & $\mathrm{R} 80(\mathrm{~m} / \mathrm{dt})$ & $\mathrm{Q} 80(\mathrm{~m} / \mathrm{dt})$ & $\mathrm{Q} 80(\mathrm{l} / \mathrm{dt})$ \\
\hline 1 & Jan & 0 & 0 & 0,00 & 0 \\
\hline 2 & Feb & 0 & 0 & 0,00 & 0 \\
\hline 3 & Mar & 0 & 0 & 0,00 & 0 \\
\hline 4 & Apr & 0 & 0 & 0,00 & 0 \\
\hline 5 & Mei & 0 & 0 & 0,00 & 0 \\
\hline 6 & Jun & 0 & 0 & 0,00 & 0 \\
\hline 7 & Jul & 0 & 0 & 0,00 & 0 \\
\hline 8 & Ags & 0 & 0 & 0,00 & 0 \\
\hline 9 & Sep & 0 & 0 & 0,00 & 0 \\
\hline 10 & Okt & 0 & 0 & 0,00 & 0 \\
\hline 11 & Nov & 0 & 0 & 0,00 & 0 \\
\hline 12 & Des & 0 & 0 & 0,00 & 0 \\
\hline
\end{tabular}


Tabel 4.8 Hasil Pemilihan Curah Hujan Efektif Sei Guha

\begin{tabular}{|c|c|c|c|c|c|c|c|c|c|c|c|c|}
\hline Tahun/Bulan & Januari & Februari & Maret & April & Mei & Juni & Juli & Aqustus & September & Oktober & November & Desember \\
\hline 2007 & 112 & 129 & 99 & 180 & 105 & 70 & 77 & 28 & 45 & 55 & 105 & 154 \\
\hline 2008 & 78 & 37 & 70 & 64 & 59 & 72 & 86 & 74 & 26 & 62 & 145 & 181 \\
\hline 2009 & 145 & 99 & 175 & 103 & 50 & 35 & 38 & 0 & 44 & 179 & 130 & 135 \\
\hline 2010 & 144 & 120 & 92 & 222 & 237 & 190 & 176 & 304 & 219 & 209 & 59 & 128 \\
\hline 2011 & 134 & 133 & 153 & 112 & 101 & 39 & 23 & 34 & 81 & 107 & 146 & 175 \\
\hline 2012 & 148 & 182 & 160 & 84 & 48 & 50 & 57 & 47 & 20 & 101 & 193 & 169 \\
\hline 2013 & 111 & 180 & 105 & 108 & 119 & 38 & 77 & 81 & 109 & 76 & 107 & 126 \\
\hline 2014 & 81 & 59 & 75 & 47 & 58 & 36 & 7 & 8 & 4 & 32 & 64 & 72 \\
\hline 2015 & 42 & 24 & 25 & 15 & 16 & 15 & 0 & 0 & 0 & 0 & 0 & 0 \\
\hline 2016 & 0 & 0 & 0 & 0 & 0 & 0 & 0 & 0 & 0 & 0 & 0 & 0 \\
\hline
\end{tabular}

Tabel 4.9 Hasil Pemilihan Curah Hujan Efektif Sei Guha (setelah diurutkan)

\begin{tabular}{|c|c|c|c|c|c|c|c|c|c|c|c|c|c|c|}
\hline No & Tahun & Januari & Februari & Maret & April & Mei & Juni & Juli & Agustus & September & Oktober & November & Desember & Probabilitas \\
\hline 1 & 2007 & 168 & 197 & 207 & 259 & 303 & 228 & 208 & 349 & 271 & 226 & 209 & 214 & $9,09 \%$ \\
\hline 2 & 2008 & 158 & 190 & 177 & 251 & 146 & 97 & 107 & 93 & 114 & 225 & 173 & 206 & $18,18 \%$ \\
\hline 3 & 2009 & 156 & 180 & 154 & 139 & 138 & 77 & 91 & 86 & 81 & 126 & 159 & 176 & $27,27 \%$ \\
\hline 4 & 2010 & 154 & 148 & 138 & 132 & 109 & 55 & 80 & 51 & 63 & 119 & 148 & 172 & $36,36 \%$ \\
\hline 5 & 2011 & 148 & 133 & 128 & 115 & 81 & 50 & 74 & 39 & 49 & 89 & 146 & 149 & $45,45 \%$ \\
\hline 6 & 2012 & 118 & 115 & 120 & 99 & 57 & 44 & 37 & 34 & 26 & 77 & 109 & 144 & $54,55 \%$ \\
\hline 7 & 2013 & 109 & 72 & 97 & 89 & 55 & 41 & 26 & 12 & 25 & 61 & 89 & 130 & 63,644 \\
\hline 8 & 2014 & 82 & 51 & 91 & 66 & 48 & 31 & 10 & 0 & 5 & 45 & 48 & 101 & $72,73 \%$ \\
\hline 9 & 2015 & 59 & 33 & 35 & 21 & 23 & 21 & 0 & 0 & 0 & 0 & 0 & 0 & $81,82 \%$ \\
\hline 10 & 2016 & 0 & 0 & 0 & 0 & 0 & 0 & 0 & 0 & 0 & 0 & 0 & 0 & 90,919 \\
\hline
\end{tabular}


Tabel 4.10 Pemilihan Curah Hujan Efektif (Re) untuk Tanaman Padi

\begin{tabular}{|r|c|c|c|c|c|}
\hline No & Bulan & $\mathrm{R} 80(\mathrm{~mm} / \mathrm{bln})$ & $\mathrm{R} 80(\mathrm{~m} / \mathrm{dt})$ & $\mathrm{Q} 80(\mathrm{~m} / \mathrm{dt})$ & $\mathrm{Q} 80(\mathrm{l} / \mathrm{dt})$ \\
\hline 1 & Jan & 64 & $2,4538 \mathrm{E}-08$ & 0,32 & 318,2112 \\
\hline 2 & Feb & 37 & $1,4125 \mathrm{E}-08$ & 0,18 & 183,1743 \\
\hline 3 & Mar & 46 & $1,7913 \mathrm{E}-08$ & 0,23 & 232,298 \\
\hline 4 & Apr & 30 & $1,152 \mathrm{E}-08$ & 0,15 & 149,3969 \\
\hline 5 & Mei & 28 & $1,0735 \mathrm{E}-08$ & 0,14 & 139,2111 \\
\hline 6 & Jun & 23 & $9,0234 \mathrm{E}-09$ & 0,12 & 117,0154 \\
\hline 7 & Jul & 2 & $7,7662 \mathrm{E}-10$ & 0,01 & 10,07116 \\
\hline 8 & Ags & 0 & 0 & 0,00 & 0 \\
\hline 9 & Sep & 1 & $3,8331 \mathrm{E}-10$ & 0,00 & 4,970747 \\
\hline 10 & Okt & 9 & $3,4864 \mathrm{E}-09$ & 0,05 & 45,21218 \\
\hline 11 & Nov & 10 & $3,7251 \mathrm{E}-09$ & 0,05 & 48,30679 \\
\hline 12 & Des & 20 & $7,7662 \mathrm{E}-09$ & 0,10 & 100,7116 \\
\hline
\end{tabular}

Sumber : Hasil Perhitungan 2017

Tabel 4. 11 Nilai Kc untuk Tanaman Padi Jenis Varietas Unggul

\begin{tabular}{|c|c|c|c|}
\hline Bulan & c1 & c2 & Kc \\
\hline \hline Okt 1 & LP & LP & LP \\
\hline Okt 2 & 1.1 & LP & LP \\
\hline Nov 1 & 1.1 & 1.1 & 1.1 \\
\hline Nov 2 & 1.05 & 1.1 & 1.08 \\
\hline Des 1 & 1.05 & 1.05 & 1.05 \\
\hline Des 2 & 0.95 & 1.05 & 1 \\
\hline Jan 1 & 0 & 0.95 & 0.475 \\
\hline Jan 2 & & 0 & 0 \\
\hline Feb 1 & LP & LP & LP \\
\hline Feb 2 & 1.1 & LP & LP \\
\hline Mar 1 & 1.1 & 1.1 & 1.1 \\
\hline Mar 2 & 1.05 & 1.1 & 1.08 \\
\hline Apr 1 & 1.05 & 1.05 & 1.05 \\
\hline Apr 2 & 0.95 & 1.05 & 1 \\
\hline Mei 1 & 0 & 0.95 & 0.475 \\
\hline Mei 2 & & 0 & 0 \\
\hline
\end{tabular}

Sumber : Dirjen Pengairan, Dep. Pu, 1998 
Tabel 4.12 Kebutuhan Air Irigasi pada Golongan A Janggi

\begin{tabular}{|c|c|c|c|c|c|c|c|c|c|c|c|c|c|}
\hline \multirow[b]{2}{*}{ PERIODE } & \multirow[b]{2}{*}{$\begin{array}{|cc|}\text { IR } & \text { saat } \\
\text { (mm/hari) }\end{array}$} & \multicolumn{12}{|c|}{ Kebutuhan Air Golongan A } \\
\hline & & PERIODE & $\begin{array}{c}\text { Eto } \\
(\mathrm{mm} / \mathrm{h})\end{array}$ & $P(\mathrm{~mm} / \mathrm{h})$ & $\begin{array}{c}\mathrm{Re} \\
(\mathrm{mm} / \mathrm{h})\end{array}$ & $\begin{array}{c}\text { WLR } \\
(\mathrm{mm} / \mathrm{h})\end{array}$ & $\mathrm{C} 1$ & $\mathrm{C} 2$ & C3 & $C^{\prime}$ & Etc & NFR & DR \\
\hline Agust-01 & 11,65 & Agust-01 & 4,74 & 2 & 0,03 & & $\mathrm{LP}$ & LP & $\mathrm{LP}$ & 11,65 & 11,65 & 13,63 & 2,43 \\
\hline Agust-02 & 11,65 & Agust-02 & 4,74 & 2 & 0,03 & & 1,1 & LP & LP & 11,65 & 11,65 & 13,62 & 2,43 \\
\hline Sep-01 & 11,98 & Sep-01 & 4,79 & 2 & 0,23 & & 1,1 & 1,1 & LP & 11,98 & 11,98 & 13,75 & 2,45 \\
\hline Sep-02 & 11,98 & Sep-02 & 4,79 & 2 & 0,26 & 1,1 & 1,05 & 1,1 & 1,1 & 1,08 & 5,19 & 8,03 & 1,43 \\
\hline Okt-01 & 12,50 & Okt-01 & 4,47 & 2 & 2,19 & 1,1 & 1,05 & 1,05 & 1,1 & 1,07 & 4,76 & 5,68 & 1,01 \\
\hline Okt-02 & 12,50 & Okt-02 & 4,47 & 2 & 2,33 & 2,2 & 0,95 & 1,05 & 1,05 & 1,02 & 4,54 & 6,41 & 1,14 \\
\hline Nop-01 & 12,64 & Nop-01 & 3,58 & 2 & 7,33 & 1,1 & 0 & 0,95 & 1,05 & 0,67 & 2,39 & $-1,84$ & 0,00 \\
\hline Nop-02 & 12,64 & Nop-02 & 3,58 & 2 & 8,37 & 1,1 & 0 & 0 & 0,95 & 0,32 & 1,13 & $-4,14$ & 0,00 \\
\hline Des-01 & 12,98 & Des-01 & 3,70 & 2 & 8,28 & & 0 & 0 & 0 & 0,00 & 0,00 & $-6,28$ & 0,00 \\
\hline Des-02 & 12,98 & Des-02 & 3,70 & 2 & 9,46 & & $\mathrm{LP}$ & LP & $\mathrm{LP}$ & 12,98 & 12,98 & 5,52 & 0,98 \\
\hline Jan-01 & 12,73 & Jan-01 & 3,67 & 2 & 9,00 & & 1,1 & LP & $\mathrm{LP}$ & 12,73 & 12,73 & 5,73 & 1,02 \\
\hline Jan-02 & 12,73 & Jan-02 & 3,67 & 2 & 9,60 & & 1,1 & 1,1 & LP & 12,73 & 12,73 & 5,13 & 0,91 \\
\hline Feb-01 & 12,67 & Feb-01 & 3,87 & 2 & 6,10 & 1,1 & 1,05 & 1,1 & 1,1 & 1,08 & 4,19 & 1,19 & 0,21 \\
\hline Feb-02 & 12,67 & Feb-02 & 3,87 & 2 & 8,13 & 1,1 & 1,05 & 1,05 & 1,1 & 1,07 & 4,12 & $-0,91$ & 0,00 \\
\hline Mar-01 & 12,41 & Mar-01 & 4,43 & 2 & 6,71 & 2,2 & 0,95 & 1,05 & 1,05 & 1,02 & 4,50 & 1,99 & 0,36 \\
\hline Mar-02 & 12,41 & Mar-02 & 4,43 & 2 & 7,15 & 1,1 & 0 & 0,95 & 1,05 & 0,67 & 2,95 & $-1,10$ & 0,00 \\
\hline Apr-01 & 11,48 & Apr-01 & 5,31 & 2 & 7,28 & 1,1 & 0,5 & 0 & 0,95 & 0,48 & 2,56 & $-1,62$ & 0,00 \\
\hline Apr-02 & 11,48 & Apr-02 & 5,31 & 2 & 8,32 & & 0,75 & 0,5 & 0 & 0,42 & 2,21 & $-4,11$ & 0,00 \\
\hline Mei-01 & 11,14 & Mei-01 & 4,99 & 2 & 7,00 & & 1 & 0,75 & 0,5 & 0,75 & 3,74 & $-1,26$ & 0,00 \\
\hline Mei-02 & 11,14 & Mei-02 & 4,99 & 2 & 7,47 & & 1 & 1 & 0,75 & 0,92 & 4,57 & $-0,89$ & 0,00 \\
\hline Jun-01 & 10,85 & Jun-01 & 5,11 & 2 & 3,38 & & 0,82 & 1 & 1 & 0,94 & 4,81 & 3,43 & 0,61 \\
\hline Jun-02 & 10,85 & Jun-02 & 5,11 & 2 & 3,86 & & 0,45 & 0,82 & 1 & 0,76 & 3,87 & 2,01 & 0,36 \\
\hline Jul-01 & 10,93 & Jul-01 & 5,14 & 2 & 6,36 & & 0 & 0,45 & 0,82 & 0,42 & 2,18 & $-2,18$ & 0,00 \\
\hline Jul-02 & 10,93 & Jul-02 & 5,14 & 2 & 6,78 & & 0 & 0 & 0,45 & 0,15 & 0,77 & $-4,01$ & 0,00 \\
\hline
\end{tabular}


Tabel 4.13 Kebutuhan Air Irigasi pada Golongan B Janggi

\begin{tabular}{|c|c|c|c|c|c|c|c|c|c|c|c|c|c|}
\hline \multirow[b]{2}{*}{ PERIODE } & \multirow[b]{2}{*}{$\begin{array}{l}\text { IR saat LP } \\
\text { (mm/hari) }\end{array}$} & \multicolumn{12}{|c|}{ Kebutuhan Air Golongan B } \\
\hline & & PERIODE & $\begin{array}{c}\text { Eto } \\
(\mathrm{mm} / \mathrm{h})\end{array}$ & $\mathrm{P}(\mathrm{mm} / \mathrm{h})$ & $\begin{array}{c}\mathrm{Re} \\
(\mathrm{mm} / \mathrm{h})\end{array}$ & $\begin{array}{c}\text { WLR } \\
(\mathrm{mm} / \mathrm{h})\end{array}$ & C1 & $\mathrm{C} 2$ & C3 & $C^{\prime}$ & Etc & NFR & DR \\
\hline Agust-01 & 11,65 & Agust-01 & 4,74 & 2 & 0,03 & & 0 & 0 & 0,45 & 0,15 & 0,71 & 2,69 & 0,48 \\
\hline Agust-02 & 11,65 & Agust-02 & 4,74 & 2 & 0,03 & & LP & LP & LP & 11,65 & 11,65 & 13,62 & 2,43 \\
\hline Sep-01 & 11,98 & Sep-01 & 4,79 & 2 & 0,23 & & 1,1 & LP & LP & 11,98 & 11,98 & 13,75 & 2,45 \\
\hline Sep-02 & 11,98 & Sep-02 & 4,79 & 2 & 0,26 & & 1,1 & 1,1 & LP & 11,98 & 11,98 & 13,72 & 2,44 \\
\hline Okt-01 & 12,50 & Okt-01 & 4,47 & 2 & 2,19 & 1,1 & 1,05 & 1,1 & 1,1 & 1,08 & 4,84 & 5,75 & 1,02 \\
\hline Okt-02 & 12,50 & Okt-02 & 4,47 & 2 & 2,33 & 1,1 & 1,05 & 1,05 & 1,1 & 1,07 & 4,76 & 5,53 & 0,98 \\
\hline Nop-01 & 12,64 & Nop-01 & 3,58 & 2 & 7,33 & 2,2 & 0,95 & 1,05 & 1,05 & 1,02 & 3,64 & 0,51 & 0,09 \\
\hline Nop-02 & 12,64 & Nop-02 & 3,58 & 2 & 8,37 & 1,1 & 0 & 0,95 & 1,05 & 0,67 & 2,39 & $-2,89$ & 0,00 \\
\hline Des-01 & 12,98 & Des-01 & 3,70 & 2 & 8,28 & 1,1 & 0 & 0 & 0,95 & 0,32 & 1,17 & $-4,01$ & 0,00 \\
\hline Des-02 & 12,98 & Des-02 & 3,70 & 2 & 9,46 & & 0 & 0 & 0 & 0,00 & 0,00 & $-7,46$ & 0,00 \\
\hline Jan-01 & 12,73 & Jan-01 & 3,67 & 2 & 9,00 & & LP & $\mathrm{LP}$ & LP & 12,73 & 12,73 & 5,73 & 1,02 \\
\hline Jan-02 & 12,73 & Jan-02 & 3,67 & 2 & 9,60 & & 1,1 & LP & LP & 12,73 & 12,73 & 5,13 & 0,91 \\
\hline Feb-01 & 12,67 & Feb-01 & 3,87 & 2 & 6,10 & & 1,1 & 1,1 & LP & 12,67 & 12,67 & 8,57 & 1,53 \\
\hline Feb-02 & 12,67 & Feb-02 & 3,87 & 2 & 8,13 & 1,1 & 1,05 & 1,1 & 1,1 & 1,08 & 4,19 & $-0,84$ & 0,00 \\
\hline Mar-01 & 12,41 & Mar-01 & 4,43 & 2 & 6,71 & 1,1 & 1,05 & 1,05 & 1,1 & 1,07 & 4,72 & 1,12 & 0,20 \\
\hline Mar-02 & 12,41 & Mar-02 & 4,43 & 2 & 7,15 & 2,2 & 0,95 & 1,05 & 1,05 & 1,02 & 4,50 & 1,55 & 0,28 \\
\hline Apr-01 & 11,48 & Apr-01 & 5,31 & 2 & 7,28 & 1,1 & 0 & 0,95 & 1,05 & 0,67 & 3,54 & $-0,64$ & 0,00 \\
\hline Apr-02 & 11,48 & Apr-02 & 5,31 & 2 & 8,32 & 1,1 & 0,5 & 0 & 0,95 & 0,48 & 2,56 & $-2,66$ & 0,00 \\
\hline Mei-01 & 11,14 & Mei-01 & 4,99 & 2 & 7,00 & & 0,75 & 0,5 & 0 & 0,42 & 2,08 & $-2,92$ & 0,00 \\
\hline Mei-02 & 11,14 & Mei-02 & 4,99 & 2 & 7,47 & & 1 & 0,75 & 0,5 & 0,75 & 3,74 & $-1,73$ & 0,00 \\
\hline Jun-01 & 10,85 & Jun-01 & 5,11 & 2 & 3,38 & & 1 & 1 & 0,75 & 0,92 & 4,69 & 3,31 & 0,59 \\
\hline Jun-02 & 10,85 & Jun-02 & 5,11 & 2 & 3,86 & & 0,82 & 1 & 1 & 0,94 & 4,81 & 2,95 & 0,53 \\
\hline Jul-01 & 10,93 & Jul-01 & 5,14 & 2 & 6,36 & & 0,45 & 0,82 & 1 & 0,76 & 3,89 & $-0,47$ & 0,00 \\
\hline Jul-02 & 10,93 & Jul-02 & 5,14 & 2 & 6,78 & & 0 & 0,45 & 0,82 & 0,42 & 2,18 & $-2,61$ & 0,00 \\
\hline
\end{tabular}

Sumber : Hasil Perhitungan 2017

Jurnal Pendidikan Teknologi dan Kejuruan BALANGA 
Tabel 4.14 Kebutuhan Air Irigasi pada Golongan C Janggi

\begin{tabular}{|c|c|c|c|c|c|c|c|c|c|c|c|c|c|}
\hline \multirow[b]{2}{*}{ PERIODE } & \multirow[b]{2}{*}{$\begin{array}{l}\text { IR saat LP } \\
\text { (mm/hari) }\end{array}$} & \multicolumn{12}{|c|}{ Kebutuhan Air Golongan C } \\
\hline & & PERIODE & $\begin{array}{c}\text { Eto } \\
(\mathrm{mm} / \mathrm{h})\end{array}$ & $P(\mathrm{~mm} / \mathrm{h})$ & $\begin{array}{c}\mathrm{Re} \\
(\mathrm{mm} / \mathrm{h})\end{array}$ & $\begin{array}{c}\text { WLR } \\
(\mathrm{mm} / \mathrm{h})\end{array}$ & $\mathrm{C} 1$ & $\mathrm{C} 2$ & $\mathrm{C} 3$ & $C^{\prime}$ & Etc & NFR & DR \\
\hline Agust-01 & 11,65 & Agust-01 & 4,74 & 2 & 0,03 & & 0 & 0,45 & 0,82 & 0,42 & 2,01 & 3,98 & 0,71 \\
\hline Agust-02 & 11,65 & Agust-02 & 4,74 & 2 & 0,03 & & 0 & 0 & 0,45 & 0,15 & 0,71 & 2,68 & 0,48 \\
\hline Sep-01 & 11,98 & Sep-01 & 4,79 & 2 & 0,23 & & LP & LP & LP & 11,98 & 11,98 & 13,75 & 2,45 \\
\hline Sep-02 & 11,98 & Sep-02 & 4,79 & 2 & 0,26 & & 1,1 & LP & $\mathrm{LP}$ & 11,98 & 11,98 & 13,72 & 2,44 \\
\hline Okt-01 & 12,50 & Okt-01 & 4,47 & 2 & 2,19 & & 1,1 & 1,1 & LP & 12,50 & 12,50 & 12,31 & 2,19 \\
\hline Okt-02 & 12,50 & Okt-02 & 4,47 & 2 & 2,33 & 1,1 & 1,05 & 1,1 & 1,1 & 1,08 & 4,84 & 5,61 & 1,00 \\
\hline Nop-01 & 12,64 & Nop-01 & 3,58 & 2 & 7,33 & 1,1 & 1,05 & 1,05 & 1,1 & 1,07 & 3,82 & $-0,41$ & 0,00 \\
\hline Nop-02 & 12,64 & Nop-02 & 3,58 & 2 & 8,37 & 2,2 & 0,95 & 1,05 & 1,05 & 1,02 & 3,64 & $-0,53$ & 0,00 \\
\hline Des-01 & 12,98 & Des-01 & 3,70 & 2 & 8,28 & 1,1 & 0 & 0,95 & 1,05 & 0,67 & 2,47 & $-2,71$ & 0,00 \\
\hline Des-02 & 12,98 & Des-02 & 3,70 & 2 & 9,46 & 1,1 & 0 & 0 & 0,95 & 0,32 & 1,17 & $-5,19$ & 0,00 \\
\hline Jan-01 & 12,73 & Jan-01 & 3,67 & 2 & 9,00 & & 0 & 0 & 0 & 0,00 & 0,00 & $-7,00$ & 0,00 \\
\hline Jan-02 & 12,73 & Jan-02 & 3,67 & 2 & 9,60 & & LP & LP & LP & 12,73 & 12,73 & 5,13 & 0,91 \\
\hline Feb-01 & 12,67 & Feb-01 & 3,87 & 2 & 6,10 & & 1,1 & LP & $\mathrm{LP}$ & 12,67 & 12,67 & 8,57 & 1,53 \\
\hline Feb-02 & 12,67 & Feb-02 & 3,87 & 2 & 8,13 & & 1,1 & 1,1 & $\mathrm{LP}$ & 12,67 & 12,67 & 6,54 & 1,16 \\
\hline Mar-01 & 12,41 & Mar-01 & 4,43 & 2 & 6,71 & 1,1 & 1,05 & 1,1 & 1,1 & 1,08 & 4,80 & 1,19 & 0,21 \\
\hline Mar-02 & 12,41 & Mar-02 & 4,43 & 2 & 7,15 & 1,1 & 1,05 & 1,05 & 1,1 & 1,07 & 4,72 & 0,67 & 0,12 \\
\hline Apr-01 & 11,48 & Apr-01 & 5,31 & 2 & 7,28 & 2,2 & 0,95 & 1,05 & 1,05 & 1,02 & 5,39 & 2,31 & 0,41 \\
\hline Apr-02 & 11,48 & Apr-02 & 5,31 & 2 & 8,32 & 1,1 & 0 & 0,95 & 1,05 & 0,67 & 3,54 & $-1,68$ & 0,00 \\
\hline Mei-01 & 11,14 & Mei-01 & 4,99 & 2 & 7,00 & 1,1 & 0,5 & 0 & 0,95 & 0,48 & 2,41 & $-1,49$ & 0,00 \\
\hline Mei-02 & 11,14 & Mei-02 & 4,99 & 2 & 7,47 & & 0,75 & 0,5 & 0 & 0,42 & 2,08 & $-3,39$ & 0,00 \\
\hline Jun-01 & 10,85 & Jun-01 & 5,11 & 2 & 3,38 & & 1 & 0,75 & 0,5 & 0,75 & 3,84 & 2,46 & 0,44 \\
\hline Jun-02 & 10,85 & Jun-02 & 5,11 & 2 & 3,86 & & 1 & 1 & 0,75 & 0,92 & 4,69 & 2,83 & 0,50 \\
\hline Jul-01 & 10,93 & Jul-01 & 5,14 & 2 & 6,36 & & 0,82 & 1 & 1 & 0,94 & 4,83 & 0,47 & 0,08 \\
\hline Jul-02 & 10,93 & Jul-02 & 5,14 & 2 & 6,78 & & 0,45 & 0,82 & 1 & 0,76 & 3,89 & $-0,89$ & 0,00 \\
\hline
\end{tabular}

Sumber : Hasil Perhitungan 2017

Jurnal Pendidikan Teknologi dan Kejuruan BALANGA 
Tabel 4.15 Kebutuhan Air Irigasi pada Golongan A Sei Guha

\begin{tabular}{|c|c|c|c|c|c|c|c|c|c|c|c|c|c|}
\hline \multirow[b]{2}{*}{ PERIODE } & \multirow[b]{2}{*}{$\begin{array}{l}\text { IR saat LP } \\
\text { (mm/hari) }\end{array}$} & \multicolumn{12}{|c|}{ Kebutuhan Air Golongan A } \\
\hline & & PERIODE & $\begin{array}{c}\text { Eto } \\
(\mathrm{mm} / \mathrm{h})\end{array}$ & $\mathrm{P}(\mathrm{mm} / \mathrm{h})$ & $\begin{array}{c}\mathrm{Re} \\
(\mathrm{mm} / \mathrm{h})\end{array}$ & $\begin{array}{c}\text { WLR } \\
(\mathrm{mm} / \mathrm{h})\end{array}$ & $\mathrm{C} 1$ & $\mathrm{C} 2$ & C3 & $C^{\prime}$ & Etc & NFR & DR \\
\hline Agust-01 & 11,65 & Agust-01 & 4,74 & 2 & 0,03 & & $\mathrm{LP}$ & $\mathrm{LP}$ & $\mathrm{LP}$ & 11,65 & 11,65 & 13,63 & 2,43 \\
\hline Agust-02 & 11,65 & Agust-02 & 4,74 & 2 & 0,03 & & 1,1 & $\mathrm{LP}$ & $\mathrm{LP}$ & 11,65 & 11,65 & 13,62 & 2,43 \\
\hline Sep-01 & 11,98 & Sep-01 & 4,79 & 2 & 0,23 & & 1,1 & 1,1 & $\mathrm{LP}$ & 11,98 & 11,98 & 13,75 & 2,45 \\
\hline Sep-02 & 11,98 & Sep-02 & 4,79 & 2 & 0,26 & 1,1 & 1,05 & 1,1 & 1,1 & 1,08 & 5,19 & 8,03 & 1,43 \\
\hline Okt-01 & 12,50 & Okt-01 & 4,47 & 2 & 2,19 & 1,1 & 1,05 & 1,05 & 1,1 & 1,07 & 4,76 & 5,68 & 1,01 \\
\hline Okt-02 & 12,50 & Okt-02 & 4,47 & 2 & 2,33 & 2,2 & 0,95 & 1,05 & 1,05 & 1,02 & 4,54 & 6,41 & 1,14 \\
\hline Nop-01 & 12,64 & Nop-01 & 3,58 & 2 & 7,33 & 1,1 & 0 & 0,95 & 1,05 & 0,67 & 2,39 & $-1,84$ & 0,00 \\
\hline Nop-02 & 12,64 & Nop-02 & 3,58 & 2 & 8,37 & 1,1 & 0 & 0 & 0,95 & 0,32 & 1,13 & $-4,14$ & 0,00 \\
\hline Des-01 & 12,98 & Des-01 & 3,70 & 2 & 8,28 & & 0 & 0 & 0 & 0,00 & 0,00 & $-6,28$ & 0,00 \\
\hline Des-02 & 12,98 & Des-02 & 3,70 & 2 & 9,46 & & $\mathrm{LP}$ & $\mathrm{LP}$ & $\mathrm{LP}$ & 12,98 & 12,98 & 5,52 & $0,9 \varepsilon$ \\
\hline Jan-01 & 12,73 & Jan-01 & 3,67 & 2 & 9,00 & & 1,1 & $\mathrm{LP}$ & $\mathrm{LP}$ & 12,73 & 12,73 & 5,73 & 1,02 \\
\hline Jan-02 & 12,73 & Jan-02 & 3,67 & 2 & 9,60 & & 1,1 & 1,1 & $\mathrm{LP}$ & 12,73 & 12,73 & 5,13 & 0,91 \\
\hline Feb-01 & 12,67 & Feb-01 & 3,87 & 2 & 6,10 & 1,1 & 1,05 & 1,1 & 1,1 & 1,08 & 4,19 & 1,19 & 0,21 \\
\hline Feb-02 & 12,67 & Feb-02 & 3,87 & 2 & 8,13 & 1,1 & 1,05 & 1,05 & 1,1 & 1,07 & 4,12 & $-0,91$ & 0,00 \\
\hline Mar-01 & 12,41 & Mar-01 & 4,43 & 2 & 6,71 & 2,2 & 0,95 & 1,05 & 1,05 & 1,02 & 4,50 & 1,99 & 0,36 \\
\hline Mar-02 & 12,41 & Mar-02 & 4,43 & 2 & 7,15 & 1,1 & 0 & 0,95 & 1,05 & 0,67 & 2,95 & $-1,10$ & 0,00 \\
\hline Apr-01 & 11,48 & Apr-01 & 5,31 & 2 & 7,28 & 1,1 & 0,5 & 0 & 0,95 & 0,48 & 2,56 & $-1,62$ & 0,00 \\
\hline Apr-02 & 11,48 & Apr-02 & 5,31 & 2 & 8,32 & & 0,75 & 0,5 & 0 & 0,42 & 2,21 & $-4,11$ & 0,00 \\
\hline Mei-01 & 11,14 & Mei-01 & 4,99 & 2 & 7,00 & & 1 & 0,75 & 0,5 & 0,75 & 3,74 & $-1,26$ & 0,00 \\
\hline Mei-02 & 11,14 & Mei-02 & 4,99 & 2 & 7,47 & & 1 & 1 & 0,75 & 0,92 & 4,57 & $-0,89$ & 0,00 \\
\hline Jun-01 & 10,85 & Jun-01 & 5,11 & 2 & 3,38 & & 0,82 & 1 & 1 & 0,94 & 4,81 & 3,43 & 0,61 \\
\hline Jun-02 & 10,85 & Jun-02 & 5,11 & 2 & 3,86 & & 0,45 & 0,82 & 1 & 0,76 & 3,87 & 2,01 & 0,36 \\
\hline Jul-01 & 10,93 & Jul-01 & 5,14 & 2 & 6,36 & & 0 & 0,45 & 0,82 & 0,42 & 2,18 & $-2,18$ & 0,00 \\
\hline Jul-02 & 10,93 & Jul-02 & 5,14 & 2 & 6,78 & & 0 & 0 & 0,45 & 0,15 & 0,77 & $-4,01$ & 0,00 \\
\hline
\end{tabular}
Sumber : Hasil Perhitungan 2017 
Tabel 4.16 Kebutuhan Air Irigasi pada Golongan B Sei Guha

\begin{tabular}{|c|c|c|c|c|c|c|c|c|c|c|c|c|c|}
\hline \multirow[b]{2}{*}{ PERIODE } & \multirow[b]{2}{*}{$\begin{array}{l}\text { IR saat LP } \\
\text { (mm/hari) }\end{array}$} & \multicolumn{12}{|c|}{ Kebutuhan Air Golongan B } \\
\hline & & PERIODE & $\begin{array}{c}\text { Eto } \\
(\mathrm{mm} / \mathrm{h})\end{array}$ & $P(\mathrm{~mm} / \mathrm{h})$ & $\begin{array}{c}\mathrm{Re} \\
(\mathrm{mm} / \mathrm{h})\end{array}$ & $\begin{array}{c}\text { WLR } \\
(\mathrm{mm} / \mathrm{h})\end{array}$ & $\mathrm{C} 1$ & $\mathrm{C} 2$ & $\mathrm{C} 3$ & $C^{\prime}$ & Etc & NFR & DR \\
\hline Agust-01 & 11,65 & Agust-01 & 4,74 & 2 & 0,03 & & 0 & 0 & 0,45 & 0,15 & 0,71 & 2,69 & 0,48 \\
\hline Agust-02 & 11,65 & Agust-02 & 4,74 & 2 & 0,03 & & LP & LP & LP & 11,65 & 11,65 & 13,62 & 2,43 \\
\hline Sep-01 & 11,98 & Sep-01 & 4,79 & 2 & 0,23 & & 1,1 & LP & $\mathrm{LP}$ & 11,98 & 11,98 & 13,75 & 2,45 \\
\hline Sep-02 & 11,98 & Sep-02 & 4,79 & 2 & 0,26 & & 1,1 & 1,1 & LP & 11,98 & 11,98 & 13,72 & 2,44 \\
\hline Okt-01 & 12,50 & Okt-01 & 4,47 & 2 & 2,19 & 1,1 & 1,05 & 1,1 & 1,1 & 1,08 & 4,84 & 5,75 & 1,02 \\
\hline Okt-02 & 12,50 & Okt-02 & 4,47 & 2 & 2,33 & 1,1 & 1,05 & 1,05 & 1,1 & 1,07 & 4,76 & 5,53 & 0,98 \\
\hline Nop-01 & 12,64 & Nop-01 & 3,58 & 2 & 7,33 & 2,2 & 0,95 & 1,05 & 1,05 & 1,02 & 3,64 & 0,51 & 0,09 \\
\hline Nop-02 & 12,64 & Nop-02 & 3,58 & 2 & 8,37 & 1,1 & 0 & 0,95 & 1,05 & 0,67 & 2,39 & $-2,89$ & 0,00 \\
\hline Des-01 & 12,98 & Des-01 & 3,70 & 2 & 8,28 & 1,1 & 0 & 0 & 0,95 & 0,32 & 1,17 & $-4,01$ & 0,00 \\
\hline Des-02 & 12,98 & Des-02 & 3,70 & 2 & 9,46 & & 0 & 0 & 0 & 0,00 & 0,00 & $-7,46$ & 0,00 \\
\hline Jan-01 & 12,73 & Jan-01 & 3,67 & 2 & 9,00 & & LP & LP & LP & 12,73 & 12,73 & 5,73 & 1,02 \\
\hline Jan-02 & 12,73 & Jan-02 & 3,67 & 2 & 9,60 & & 1,1 & LP & LP & 12,73 & 12,73 & 5,13 & 0,91 \\
\hline Feb-01 & 12,67 & Feb-01 & 3,87 & 2 & 6,10 & & 1,1 & 1,1 & LP & 12,67 & 12,67 & 8,57 & 1,53 \\
\hline Feb-02 & 12,67 & Feb-02 & 3,87 & 2 & 8,13 & 1,1 & 1,05 & 1,1 & 1,1 & 1,08 & 4,19 & $-0,84$ & 0,00 \\
\hline Mar-01 & 12,41 & Mar-01 & 4,43 & 2 & 6,71 & 1,1 & 1,05 & 1,05 & 1,1 & 1,07 & 4,72 & 1,12 & 0,20 \\
\hline Mar-02 & 12,41 & Mar-02 & 4,43 & 2 & 7,15 & 2,2 & 0,95 & 1,05 & 1,05 & 1,02 & 4,50 & 1,55 & 0,28 \\
\hline Apr-01 & 11,48 & Apr-01 & 5,31 & 2 & 7,28 & 1,1 & 0 & 0,95 & 1,05 & 0,67 & 3,54 & $-0,64$ & 0,00 \\
\hline Apr-02 & 11,48 & Apr-02 & 5,31 & 2 & 8,32 & 1,1 & 0,5 & 0 & 0,95 & 0,48 & 2,56 & $-2,66$ & 0,00 \\
\hline Mei-01 & 11,14 & Mei-01 & 4,99 & 2 & 7,00 & & 0,75 & 0,5 & 0 & 0,42 & 2,08 & $-2,92$ & 0,00 \\
\hline Mei-02 & 11,14 & Mei-02 & 4,99 & 2 & 7,47 & & 1 & 0,75 & 0,5 & 0,75 & 3,74 & $-1,73$ & 0,00 \\
\hline Jun-01 & 10,85 & Jun-01 & 5,11 & 2 & 3,38 & & 1 & 1 & 0,75 & 0,92 & 4,69 & 3,31 & 0,59 \\
\hline Jun-02 & 10,85 & Jun-02 & 5,11 & 2 & 3,86 & & 0,82 & 1 & 1 & 0,94 & 4,81 & 2,95 & 0,53 \\
\hline Jul-01 & 10,93 & Jul-01 & 5,14 & 2 & 6,36 & & 0,45 & 0,82 & 1 & 0,76 & 3,89 & $-0,47$ & 0,00 \\
\hline Jul-02 & 10,93 & Jul-02 & 5,14 & 2 & 6,78 & & 0 & 0,45 & 0,82 & 0,42 & 2,18 & $-2,61$ & 0,00 \\
\hline
\end{tabular}

Sumber : Hasil Perhitungan 2017

Jurnal Pendidikan Teknologi dan Kejuruan BALANGA 
Tabel 4.17 Kebutuhan Air Irigasi pada Golongan C Sei Guha

\begin{tabular}{|c|c|c|c|c|c|c|c|c|c|c|c|c|c|}
\hline \multirow[b]{2}{*}{ PERIODE } & \multirow[b]{2}{*}{$\begin{array}{l}\text { IR saat LP } \\
\text { (mm/hari) }\end{array}$} & \multicolumn{12}{|c|}{ Kebutuhan Air Golongan C } \\
\hline & & PERIODE & $\begin{array}{c}\text { Eto } \\
(\mathrm{mm} / \mathrm{h})\end{array}$ & $\mathrm{P}(\mathrm{mm} / \mathrm{h})$ & $\begin{array}{c}\mathrm{Re} \\
(\mathrm{mm} / \mathrm{h})\end{array}$ & $\begin{array}{c}\text { WLR } \\
(\mathrm{mm} / \mathrm{h})\end{array}$ & $\mathrm{C} 1$ & $\mathrm{C} 2$ & $\mathrm{C} 3$ & $C^{\prime}$ & Etc & NFR & DR \\
\hline Agust-01 & 11,65 & Agust-01 & 4,74 & 2 & 0,03 & & 0 & 0,45 & 0,82 & 0,42 & 2,01 & 3,98 & 0,71 \\
\hline Agust-02 & 11,65 & Agust-02 & 4,74 & 2 & 0,03 & & 0 & 0 & 0,45 & 0,15 & 0,71 & 2,68 & 0,48 \\
\hline Sep-01 & 11,98 & Sep-01 & 4,79 & 2 & 0,23 & & LP & LP & $\mathrm{LP}$ & 11,98 & 11,98 & 13,75 & 2,45 \\
\hline Sep-02 & 11,98 & Sep-02 & 4,79 & 2 & 0,26 & & 1,1 & LP & LP & 11,98 & 11,98 & 13,72 & 2,44 \\
\hline Okt-01 & 12,50 & Okt-01 & 4,47 & 2 & 2,19 & & 1,1 & 1,1 & LP & 12,50 & 12,50 & 12,31 & 2,19 \\
\hline Okt-02 & 12,50 & Okt-02 & 4,47 & 2 & 2,33 & 1,1 & 1,05 & 1,1 & 1,1 & 1,08 & 4,84 & 5,61 & 1,00 \\
\hline Nop-01 & 12,64 & Nop-01 & 3,58 & 2 & 7,33 & 1,1 & 1,05 & 1,05 & 1,1 & 1,07 & 3,82 & $-0,41$ & 0,00 \\
\hline Nop-02 & 12,64 & Nop-02 & 3,58 & 2 & 8,37 & 2,2 & 0,95 & 1,05 & 1,05 & 1,02 & 3,64 & $-0,53$ & 0,00 \\
\hline Des-01 & 12,98 & Des-01 & 3,70 & 2 & 8,28 & 1,1 & 0 & 0,95 & 1,05 & 0,67 & 2,47 & $-2,71$ & 0,00 \\
\hline Des-02 & 12,98 & Des-02 & 3,70 & 2 & 9,46 & 1,1 & 0 & 0 & 0,95 & 0,32 & 1,17 & $-5,19$ & 0,00 \\
\hline Jan-01 & 12,73 & Jan-01 & 3,67 & 2 & 9,00 & & 0 & 0 & 0 & 0,00 & 0,00 & $-7,00$ & 0,00 \\
\hline Jan-02 & 12,73 & Jan-02 & 3,67 & 2 & 9,60 & & LP & LP & LP & 12,73 & 12,73 & 5,13 & 0,91 \\
\hline Feb-01 & 12,67 & Feb-01 & 3,87 & 2 & 6,10 & & 1,1 & LP & $\mathrm{LP}$ & 12,67 & 12,67 & 8,57 & 1,53 \\
\hline Feb-02 & 12,67 & Feb-02 & 3,87 & 2 & 8,13 & & 1,1 & 1,1 & $\mathrm{LP}$ & 12,67 & 12,67 & 6,54 & 1,16 \\
\hline Mar-01 & 12,41 & Mar-01 & 4,43 & 2 & 6,71 & 1,1 & 1,05 & 1,1 & 1,1 & 1,08 & 4,80 & 1,19 & 0,21 \\
\hline Mar-02 & 12,41 & Mar-02 & 4,43 & 2 & 7,15 & 1,1 & 1,05 & 1,05 & 1,1 & 1,07 & 4,72 & 0,67 & 0,12 \\
\hline Apr-01 & 11,48 & Apr-01 & 5,31 & 2 & 7,28 & 2,2 & 0,95 & 1,05 & 1,05 & 1,02 & 5,39 & 2,31 & 0,41 \\
\hline Apr-02 & 11,48 & Apr-02 & 5,31 & 2 & 8,32 & 1,1 & 0 & 0,95 & 1,05 & 0,67 & 3,54 & $-1,68$ & 0,00 \\
\hline Mei-01 & 11,14 & Mei-01 & 4,99 & 2 & 7,00 & 1,1 & 0,5 & 0 & 0,95 & 0,48 & 2,41 & $-1,49$ & 0,00 \\
\hline Mei-02 & 11,14 & Mei-02 & 4,99 & 2 & 7,47 & & 0,75 & 0,5 & 0 & 0,42 & 2,08 & $-3,39$ & 0,00 \\
\hline Jun-01 & 10,85 & Jun-01 & 5,11 & 2 & 3,38 & & 1 & 0,75 & 0,5 & 0,75 & 3,84 & 2,46 & 0,44 \\
\hline Jun-02 & 10,85 & Jun-02 & 5,11 & 2 & 3,86 & & 1 & 1 & 0,75 & 0,92 & 4,69 & 2,83 & 0,50 \\
\hline Jul-01 & 10,93 & Jul-01 & 5,14 & 2 & 6,36 & & 0,82 & 1 & 1 & 0,94 & 4,83 & 0,47 & 0,08 \\
\hline Jul-02 & 10,93 & Jul-02 & 5,14 & 2 & 6,78 & & 0,45 & 0,82 & 1 & 0,76 & 3,89 & $-0,89$ & 0,00 \\
\hline
\end{tabular}
Sumber : Hasil Perhitungan 2017 
Tabel 4. 18 Prediksi Sebaran Debit Bulanan dalam Siklus Setahun Desa Kuala Kurun, Kecamatan Kurun, Kelompok Tani "Bengkel Indah" Tabel Rekapitulasi Debit

\begin{tabular}{|c|c|c|c|c|c|c|c|}
\hline \multirow[b]{2}{*}{ No. } & \multicolumn{2}{|l|}{ Lokasi } & \multirow[b]{2}{*}{ Sumber Air } & \multirow[b]{2}{*}{ Luas total (m2) } & \multirow[b]{2}{*}{ Kecepatan rata-rata (m/dtk) } & \multirow[b]{2}{*}{ Debit (m3/dtk) } & \multirow[b]{2}{*}{ Debit (liter/dtk) } \\
\hline & Desa ( Kelompok Tani ) & Kecamatan & & & & & \\
\hline 1 & Desa Ja'ar (KT Luaw Guha I-IV) & Dusun Timur & Sungai Kalu Langai & 2,150 & 0,019 & 0,040 & 40,133 \\
\hline 2 & Desa Ja'ar (KT Luaw Guha I-IV) & Dusun Timur & Sungai Guha & 3,983 & 0,036 & 0,144 & 144,034 \\
\hline 3 & Desa Ja'ar (KT Luaw Guha I-IV) & Dusun Timur & Sungai Liang & 14,175 & 0,036 & 0,508 & 507,938 \\
\hline 4 & Desa Siong Telang (KT Rungkai Janang) & Paju Epat & Sungai Siong & 5,089 & 0,243 & 1,237 & 1236,566 \\
\hline 5 & Desa Siong Telang (KT Rungkai Janang) & Paju Epat & Sungai Rungkai & 2,236 & 0,037 & 0,083 & 82,714 \\
\hline 6 & Desa Siong Telang (KT Isa Pakat) & Paju Epat & Sungai Telang & 27,148 & 0,068 & 1,855 & 1855,113 \\
\hline 7 & Desa Tangkan (KT Gandrung Harapan Wa'u 1) & Awang & Sungai Keladan & 2,013 & 0,039 & 0,079 & 79,168 \\
\hline 8 & Desa Tangkan (KT Gandrung Harapan Wa'u 2 \& 3) & Awang & Sungai Palepek & 5,400 & 0,295 & 1,591 & 1591,200 \\
\hline 9 & Desa Bambulung (KT Kuranji Raya) & Pematang Karau & Sungai Bambulung & 45,893 & 0,713 & 32,737 & 32736,650 \\
\hline 10 & Desa Bambulung (KT Bingkai Raya) & Pematang Karau & Sungai Tuyau & 20,739 & 0,668 & 13,847 & 13846,739 \\
\hline
\end{tabular}


Tabel 4.19 Hasil Survei Kondisi Sumber Air untuk Kepentingan Lahan

\begin{tabular}{|c|c|c|c|c|c|c|c|c|c|c|}
\hline \multirow[b]{3}{*}{ No } & \multirow{3}{*}{$\begin{array}{lll}\text { Desa } & \text { Tani) }\end{array}$} & \multirow[b]{3}{*}{ Kecamatan } & \multirow{3}{*}{$\begin{array}{c}\text { Daerah } \\
\text { Tangkapan } \\
\text { Air (DTA) } \\
\text { Sumber Air }\end{array}$} & \multirow{3}{*}{$\begin{array}{l}\text { Prediksi Sebaran } \\
\text { Debit Bulanan dan } \\
\text { Musimannya } \\
\text { dalam Siklus } \\
\text { Setahun }\end{array}$} & \multirow{3}{*}{$\begin{array}{c}\text { Tanggal } \\
\text { Survei }\end{array}$} & \multicolumn{5}{|c|}{ Sumber Air } \\
\hline & & & & & & \multirow[b]{2}{*}{ koordinat } & \multirow[b]{2}{*}{$\begin{array}{l}\text { Elevasi } \\
(\mathrm{m})\end{array}$} & \multicolumn{2}{|c|}{ Jenis Sumber Air } & \multirow[b]{2}{*}{$\begin{array}{c}\text { Debit Sesaa } \\
\text { (I/det) }\end{array}$} \\
\hline & & & & & & & & $\begin{array}{l}\text { Non } \\
\text { pasut }\end{array}$ & pasut & \\
\hline 1 & Jaar (Luaw Guha I, II, III \& IV) & Dusun Timur & Ada & $\begin{array}{l}\text { Tergantung Curah } \\
\text { Hujan }\end{array}$ & $13 / 06 / 2017$ & S 02 $10^{\prime} 37,0^{\prime \prime}$ E $115^{\circ} 12^{\prime} 20,0^{\prime \prime}$ & 24 & Air Permukaan & - & 40,133 \\
\hline 2 & Jaar (Luaw Guha I, II, III \& IV) & Dusun Timur & Ada & $\begin{array}{l}\text { Tergantung Curah } \\
\text { Hujan }\end{array}$ & $13 / 06 / 2017$ & S 02 $10^{\prime} 41,3^{\prime \prime}$ E $115^{\circ} 12^{\prime} 19,8^{\prime \prime}$ & 23 & Air Permukaan & - & 144,034 \\
\hline 3 & Jaar (Luaw Guha I, II, III \& IV) & Dusun Timur & Ada & $\begin{array}{l}\text { Tergantung Curah } \\
\text { Hujan }\end{array}$ & 13/06/2017 & $\begin{array}{l}\mathrm{S} 02^{\circ} 10^{\prime} 36,3^{\prime \prime} \\
115^{\circ} 13^{\prime} 03,4^{\prime \prime}\end{array}$ & 24 & Air Permukaan & - & 507,938 \\
\hline 4 & Siong (Rungkai Janang) & Paju Epat & Ada & $\begin{array}{l}\text { Tergantung Curah } \\
\text { Hujan }\end{array}$ & $14 / 06 / 2017$ & $\begin{array}{l}\mathrm{S} 02^{\circ} 05^{\prime} 36,6^{\prime \prime} \\
115^{\circ} 00^{\prime} 58,8^{\prime \prime}\end{array}$ & 2 & Air Permukaan & - & 1236,566 \\
\hline 5 & Siong (Rungkai Janang) & Paju Epat & Ada & $\begin{array}{c}\text { Tergantung Curah } \\
\text { Hujan }\end{array}$ & $14 / 06 / 2017$ & $\begin{array}{l}\mathrm{S} 02^{\circ} 05^{\prime} 31,6^{\prime \prime} \\
115^{\circ} 00^{\prime} 54,7^{\prime \prime}\end{array}$ & 5 & Air Permukaan & - & 82,714 \\
\hline 6 & Telang (Isa Pakat) & Paju Epat & Ada & $\begin{array}{l}\text { Tergantung Curah } \\
\text { Hujan }\end{array}$ & $14 / 06 / 2017$ & $\begin{array}{l}\mathrm{S} 02^{\circ} 06^{\prime} 07,3^{\prime \prime} \\
115^{\circ} 00^{\prime} 47,6^{\prime \prime}\end{array}$ & 7 & Air Permukaan & - & 1855,113 \\
\hline 7 & $\begin{array}{l}\text { Tangkan } \\
\text { (Gandrung Harapan Wau I) }\end{array}$ & Awang & Ada & $\begin{array}{c}\text { Tergantung Curah } \\
\text { Hujan }\end{array}$ & $14 / 06 / 2017$ & $\begin{array}{l}\mathrm{S} 02^{\circ} 00^{\prime} 03,7^{\prime \prime} \\
115^{\circ} 16^{\prime} 37,1^{\prime \prime}\end{array}$ & 57 & Air Permukaan & - & 79,168 \\
\hline 8 & $\begin{array}{l}\text { Tangkan } \\
\text { (Gandrung Harapan Wau II \& III) }\end{array}$ & Awang & Ada & $\begin{array}{c}\text { Tergantung Curah } \\
\text { Hujan }\end{array}$ & $14 / 06 / 2017$ & $\begin{array}{l}\text { S 0 } 01^{\circ} 59^{\prime} 44,7^{\prime \prime} \\
115^{\circ} 16^{\prime} 42,0^{\prime \prime}\end{array}$ & 51 & Air Permukaan & - & 1591,200 \\
\hline 9 & Bambulung (Bingkai Raya) & $\begin{array}{c}\text { Pematang } \\
\text { Karau }\end{array}$ & Ada & $\begin{array}{c}\text { Tergantung Curah } \\
\text { Hujan }\end{array}$ & $15 / 06 / 2017$ & $\begin{array}{l}\mathrm{S} 01^{\circ} 49^{\prime} 53,8^{\prime \prime} \\
115^{\circ} 02^{\prime} 32,2^{\prime \prime}\end{array}$ & 11 & Air Permukaan & - & 13846,739 \\
\hline 10 & Bambulung (Kuranji Raya) & $\begin{array}{c}\text { Pematang } \\
\text { Karau }\end{array}$ & Ada & $\begin{array}{l}\text { Tergantung Curah } \\
\text { Hujan }\end{array}$ & $15 / 06 / 2017$ & $\begin{array}{l}\mathrm{S} 01^{\circ} 49^{\prime} 24,8^{\prime \prime} \\
115^{\circ} 01^{\prime} 59,3^{\prime \prime}\end{array}$ & 10 & Air Permukaan & - & 32736,650 \\
\hline
\end{tabular}


Tabel 4. 20 Hasil Survei Posisi Calon Lahan Terhadap Sumber Air

\begin{tabular}{|c|c|c|c|c|c|c|c|}
\hline \multirow[b]{2}{*}{ No } & \multirow[b]{2}{*}{$\begin{array}{c}\text { Desa } \\
\text { (Kelompok Tani) }\end{array}$} & \multirow[b]{2}{*}{ Kecamatan } & \multicolumn{3}{|c|}{ Calon Lahan } & \multirow[b]{2}{*}{$\begin{array}{l}\text { Peta Situasi Titik Sumber } \\
\text { Pengambilan Air }\end{array}$} & \multirow[b]{2}{*}{$\begin{array}{c}\text { Prasarana dan Sarana Pengairan } \\
\text { yang Ada }\end{array}$} \\
\hline & & & Koordinat & $\begin{array}{l}\text { Elevasi } \\
(\mathrm{m})\end{array}$ & $\begin{array}{l}\text { Jarak Calon Lahan Ke } \\
\text { Sumber Air (Km) }\end{array}$ & & \\
\hline 1 & Jaar (Luaw Guha I) & Dusun Timur & S $02^{\circ} 10^{\prime} 45,2^{\prime \prime}$ E $115^{\circ} 11^{\prime} 55,5^{\prime \prime}$ & 8 & 0,948 & Ada & Saluran Primer \\
\hline 2 & Jaar (Luaw Guha I) & Dusun Timur & S $02^{\circ} 10^{\prime} 23,4^{\prime \prime}$ E $115^{\circ} 11^{\prime} 09,1^{\prime \prime}$ & 8 & 1,08 & Ada & Saluran Primer \\
\hline 3 & Jaar (Luaw Guha I) & Dusun Timur & S $02^{\circ} 09^{\prime} 57,4^{\prime \prime}$ E $115^{\circ} 10^{\prime} 28,8^{\prime \prime}$ & 8 & 2,43 & Ada & Saluran Primer \\
\hline 4 & Jaar (Luaw Guha II) & Dusun Timur & S $02^{\circ} 09^{\prime} 40,7^{\prime \prime}$ E $115^{\circ} 09^{\prime} 51,5^{\prime \prime}$ & 21 & 4,06 & Ada & Saluran Primer \\
\hline 5 & Jaar (Luaw Guha II) & Dusun Timur & $\mathrm{S} 02^{\circ} 10^{\prime} 23,4^{\prime \prime} \mathrm{E} 115^{\circ} 11^{\prime} 09,1^{\prime \prime}$ & 21 & 4,16 & Ada & Saluran Primer \\
\hline 6 & Jaar (Luaw Guha II) & Dusun Timur & 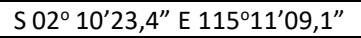 & 21 & 5,51 & Ada & Saluran Primer \\
\hline 7 & Jaar (Luaw Guha III) & Dusun Timur & S 0209'57,4" E $115^{\circ} 10^{\prime} 28,8^{\prime \prime}$ & 14 & 4,9 & Ada & Saluran Primer \\
\hline 8 & Jaar (Luaw Guha III) & Dusun Timur & S $02^{\circ} 09^{\prime} 57,4^{\prime \prime}$ E $115^{\circ} 10^{\prime} 28,8^{\prime \prime}$ & 14 & 5 & Ada & Saluran Primer \\
\hline 9 & Jaar (Luaw Guha III) & Dusun Timur & $\mathrm{S} \mathrm{S} \mathrm{02}^{\circ} 09^{\prime} 57,4^{\prime \prime}$ E $115^{\circ} 10^{\prime} 28,8^{\prime \prime}$ & 14 & 6,37 & Ada & Saluran Primer \\
\hline 10 & Jaar (Luaw Guha IV) & Dusun Timur & S 0209'40,7" E $115^{\circ} 09^{\prime} 51,5^{\prime \prime}$ & 11 & 5,93 & Ada & Saluran Primer \\
\hline 11 & Jaar (Luaw Guha IV) & Dusun Timur & S $02^{\circ} 09^{\prime} 40,7^{\prime \prime}$ E $115^{\circ} 09^{\prime} 51,5^{\prime \prime}$ & 11 & 6,1 & Ada & Saluran Primer \\
\hline 12 & Jaar (Luaw Guha IV) & Dusun Timur & S $02^{\circ} 09^{\prime} 40,7^{\prime \prime}$ E $115^{\circ} 09^{\prime} 51,5^{\prime \prime}$ & 11 & 7,41 & Ada & Saluran Primer \\
\hline 13 & Siong (Rungkai Janang) & Paju Epat & $\mathrm{S} 02^{\circ} 05^{\prime} 32,7^{\prime \prime}$ E $115^{\circ} 00^{\prime} 58,9^{\prime \prime}$ & 12 & 0,1023 & Ada & Saluran Primer \\
\hline 14 & Siong (Rungkai Janang) & Paju Epat & S $02^{\circ} 05^{\prime} 32,7^{\prime \prime}$ E $115^{\circ} 00^{\prime} 58,9^{\prime \prime}$ & 12 & 0,1385 & Ada & Saluran Primer \\
\hline 15 & Telang (Isa Pakat) & Paju Epat & S 02 $06^{\prime} 07,2^{\prime \prime}$ E $115^{\circ} 00^{\prime} 63,6^{\prime \prime}$ & 12 & 0,3685 & Ada & Saluran Primer \\
\hline 16 & $\begin{array}{l}\text { Tangkan } \\
\text { (Gandrung Harapan Wau I) }\end{array}$ & Awang & S $02^{\circ} 00^{\prime} 39,0^{\prime \prime}$ E $115^{\circ} 16^{\prime} 24,4^{\prime \prime}$ & 23 & 0,9316 & Ada & Saluran Primer \\
\hline 17 & $\begin{array}{l}\text { Tangkan } \\
\text { (Gandrung Harapan Wau II) }\end{array}$ & Awang & $\mathrm{S} 01^{\circ} 59^{\prime} 47,8^{\prime \prime}$ E $115^{\circ} 16^{\prime} 49,0^{\prime \prime}$ & 45 & 0,2355 & Ada & Saluran Primer \\
\hline 18 & $\begin{array}{l}\text { Tangkan } \\
\text { (Gandrung Harapan Wau III) }\end{array}$ & Awang & S $01^{\circ} 59^{\prime} 52,7^{\prime \prime} \mathrm{E} 115^{\circ} 16^{\prime} 59,4^{\prime \prime}$ & 39 & 0,6031 & Ada & Saluran Primer \\
\hline 19 & Bambulung (Bingai Raya) & Pematang Karau & 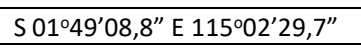 & 44 & 1,37 & Ada & Saluran Primer \\
\hline 20 & Bambulung (Kuranji Raya) & Pematang Karau & S $01^{\circ} 49^{\prime} 05,9^{\prime \prime}$ E $115^{\circ} 02^{\prime} 23,3^{\prime \prime}$ & 16 & 0,9482 & Ada & Saluran Primer \\
\hline
\end{tabular}

Sumber : Hasil Survey dan Analisis 2017 
Tabel 4.21 Rekomendasi Hasil Survei Potensi Pengairan

\begin{tabular}{|c|c|c|c|c|c|c|c|c|}
\hline \multirow[b]{2}{*}{ No } & \multicolumn{2}{|l|}{ Hasil Survey aan AnatisIs ZUII } & \multicolumn{2}{|c|}{ Ketersediaan Air } & \multicolumn{3}{|c|}{ Kebutuhan Air } & \multirow[b]{2}{*}{ Rekomendasi } \\
\hline & Desa (Kelompok Tani) & Kecamatan & $\begin{array}{l}\text { Jenis Sumber } \\
\quad \text { Air }\end{array}$ & $\begin{array}{c}\text { Ketersediaan } \\
\text { Air } \\
(\mathrm{I} / \mathrm{dt})\end{array}$ & $\begin{array}{l}\text { Luas Calon } \\
\text { Lahan } \\
\text { (Ha) }\end{array}$ & $\begin{array}{c}\text { Kebutuhan } \\
\text { Air } \\
\text { di Lahan per } \\
\text { Hektar (I/dt) }\end{array}$ & $\begin{array}{c}\text { Kebutuhan Air } \\
\text { Total di Lahan (I/dt) }\end{array}$ & \\
\hline 1 & Jaar (Luaw Guha I, II \& III) & Dusun Timur & $\begin{array}{c}\text { Sungai } \\
\text { Kalilungai }\end{array}$ & 112,382 & 3,6 & 2,45 & 8,82 & $\begin{array}{l}\text { Perlu bangunan penangkap air, } \\
\text { saluran dan pintu air. }\end{array}$ \\
\hline 2 & Jaar (Luaw Guha I, II \& III) & Dusun Timur & Sungai Guha & 112,382 & 11,1 & 2,45 & 27,195 & $\begin{array}{l}\text { Perlu bangunan penangkap air, } \\
\text { saluran dan pintu air. }\end{array}$ \\
\hline 3 & Jaar (Luaw Guha I, II \& III) & Dusun Timur & Sungai Liang & 112,382 & 24,9 & 2,45 & 61,005 & $\begin{array}{l}\text { Perlu bangunan penangkap air, } \\
\text { saluran dan pintu air. }\end{array}$ \\
\hline 4 & Siong (Rungkai Janang) & Paju Epat & Sungai Siong & 112,382 & 60 & 2,45 & 147 & $\begin{array}{l}\text { Perlu bangunan penangkap air, } \\
\text { saluran dan pintu air. }\end{array}$ \\
\hline 5 & Desa Siong Telang (KT & Paju Epat & Sungai Rungkai & 112,382 & 60 & 2,45 & 147 & $\begin{array}{l}\text { Perlu bangunan penangkap air, } \\
\text { saluran dan pintu air. }\end{array}$ \\
\hline 6 & Desa Siong Telang (KT Isa Pakat) & Paju Epat & Sungai Telang & 112,382 & 7,5 & 2,45 & 18,375 & $\begin{array}{l}\text { Perlu bangunan penangkap air, } \\
\text { saluran dan pintu air. }\end{array}$ \\
\hline 7 & Desa Tangkan (KT Gandrung Harapan Wa'u 1) & Awang & Sungai Keladan & 112,382 & 21,2 & 2,45 & 51,94 & $\begin{array}{l}\text { Perlu bangunan penangkap air, } \\
\text { saluran dan pintu air. }\end{array}$ \\
\hline 8 & Desa Tangkan (KT Gandrung Harapan Wa'u 2 \& 3) & Awang & Sungai Palepek & 112,382 & 21,2 & 2,45 & 51,94 & $\begin{array}{l}\text { Perlu bangunan penangkap air, } \\
\text { saluran dan pintu air. }\end{array}$ \\
\hline 9 & Desa Bambulung (KT Kuranji Raya) & Pematang Karau & $\begin{array}{c}\text { Sungai } \\
\text { Bambulung }\end{array}$ & 112,382 & 99,9 & 2,45 & 244,755 & $\begin{array}{l}\text { Perlu bangunan penangkap air, } \\
\text { saluran dan pintu air. }\end{array}$ \\
\hline 10 & Desa Bambulung (KT Bingkai Raya) & Pematang Karau & Sungai Tuyau & 112,382 & 43,2 & 2,45 & 105,84 & $\begin{array}{l}\text { Perlu bangunan penangkap air, } \\
\text { saluran dan pintu air. }\end{array}$ \\
\hline
\end{tabular}




\section{KESIMPULAN}

Dari pengumpulan serta pengolahan data yang dilakukan untuk merencanakan daerah irigasi kecamatan , dapat diperoleh beberapa hal sebagai berikut.

1. Sistem irigasi yang direncanakan untuk daerah irigasi Katingan dan sekitarnya adalah sistem irigasi gravitasi.

2. Jaringan irigasi yang digunakan adalah jaringan irigasi teknis.

3. Luas daerah irigasi yang dialiri adalah $352,6 \mathrm{Ha}$.

4. Petak sawah yang direncanakan adalah sebanyak 3 petak dengan luas masing-masing petak antara 3,6 ha hingga 99,9 $\mathrm{Ha}$.

5. Kebutuhan air setiap hektar sebelum disesuaikan dengan efisiensi tiap saluran direncanakan sebesar $1.2 \mathrm{l} / \mathrm{det} / \mathrm{ha}$

6. Perlu bangunan irigasi seperti penangkap air, saluran primer, sekunder, tersier dan pintu air.

\section{SARAN}

Dari pengerjaan tugas ini penulis dapat menyarankan beberapa hal sebagai berikut.

1. Untuk memperoleh perencanaan dan perhitungan yang lebih akurat, maka perlu diperhitungkan kebutuhan air yang lebih teliti, mengingat pada kenyataan di lapangan sulit sekali menemukan kondisi ideal, di mana semua kebutuhan air untuk semua areal sawah bisa dipenuhi secara bersamaan.

2. Data-data yang digunakan sebaiknya data-data yang aktual dan lengkap, sehingga penyimpangan dapat diperkecil.

\section{DAFTAR PUSTAKA}

[1]. Dinas Pekerjaan Umum Provinsi Kalimantan Tengah. 2015. Data Pengamatan Curah Hujan Tahun 2006 2015 Kabupaten Katingan. Kalimantan Tengah.

[2]. Badan Meteorologi, Klimatologi dan Geofisika. 2015 Data Klimatologi Sampit Tahun 2006-2015. Kalimantan Tengah.

[3]. Bardan, Muhammad. 2013. Irigasi. Graha Ilmu. Yogyakarta. 